\title{
On the Spatial Design of Co-Fed Amines for Selective Dehydration of Methyl Lactate to Acrylates
}

\author{
Yutong Pang ${ }^{1,2}$, M. Alexander Ardagh ${ }^{1}$, Manish Shetty ${ }^{1}$, \\ Anargyros Chatzidimitriou ${ }^{1,2}$, Gaurav Kumar ${ }^{1,2}$, \\ Bess Vlaisavljevich ${ }^{2,3^{*}}$, Paul J. Dauenhauer ${ }^{1,2^{*}}$ \\ ${ }^{1}$ Department of Chemical Engineering and Materials Science, University of Minnesota, 421 Washington Ave. SE, \\ Minneapolis, MN 55455, USA \\ ${ }^{2}$ NSF Center for Sustainable Polymers, University of Minnesota, 208 Smith Hall, 207 Pleasant Street SE, \\ Minneapolis, MN 55455, USA. \\ ${ }^{3}$ University of South Dakota, Department of Chemistry, 302 Pardee Laboratory, 414 E. Clark Street, Vermillion, SD, \\ 57069, USA. \\ *Corresponding authors: Bess.Vlaisavljevich@usd.edu, hauer@umn.edu
}

\begin{abstract}
Co-feeding an inert and site-selective chemical titrant provides desirable selectivity tuning when titrant adsorption is favored over side reaction pathways on a solid acid catalyst. Here, a selectivity enhancement from 61 to $84 \mathrm{C} \%$ was demonstrated for methyl lactate dehydration to methyl acrylate and acrylic acid over $\mathrm{NaY}$ zeolite catalyst using amines as the co-fed titrants to suppress side reactions on in situ generated Brønsted acid sites (BAS). The effectiveness of BAS titration was evaluated by considering both the basicity and steric properties of the titrant molecule with the goal to maximize the selectivity enhancement. The presence of electron-donating alkyl functional groups enhances amine basicity but also introduces additional steric constraints to the molecule with respect to the pore dimensions of the NaY zeolite. While higher basicity of titrant amines favors stronger adsorption on BAS, steric limitations hinder site binding through contributions from internal diffusion limitations and local steric repulsion between titrant and the zeolite wall around the BAS. Titrant bases with proton affinities above $\sim 1040 \mathrm{~kJ} / \mathrm{mol}$ and sizes below $85 \%$ of the $\mathrm{NaY}$ supercage window or pore diameter are predicted to afford dehydration selectivities above $90 \mathrm{C} \%$ to acrylate products.
\end{abstract}

1.0 Introduction. Selectivity control remains one of the key elements in modern catalytic processes for the suppression of competing reaction pathways. Selective catalysis affords more economical and sustainable chemical syntheses to the desirable products due to the reduction in reactant waste, toxic byproduct formation, and cost for product separation. High selectivity may be achieved by lowering the energy barrier to the preferential product by manipulating the energies of reaction intermediates and transition states via catalyst design to modify binding energies of surface species, ${ }^{1,2}$ site strength, ${ }^{3}$ or steric confinement around the active sites. ${ }^{4,5}$

Suppression of side reactions and selectivity improvement can also be achieved utilizing competitive adsorption of inert site-selective titrants on active sites if binding of the titrant is favored over the undesired pathways. ${ }^{6}$ In particular, organic bases, such as ammonia, alkyl amines, and pyridine ${ }^{7-10}$ bind on Brønsted acid sites (BAS) even at elevated temperatures above $160{ }^{\circ} \mathrm{C}$, typical for gas-phase reactions. ${ }^{3,11-13}$ However, ammonia and pyridine adsorb on both Lewis and Brønsted acid sites. $^{7,14}$ Selective BAS adsorption can be obtained using 2,6-substituted pyridines with steric constraints around the nitrogen atom. ${ }^{14-16}$ For example, introduction of 2,6-ditertbutylpyridine to modulate BAS density in heteropolyacid Keggin clusters was shown to enhance methanol oxidation selectivity to dimethoxymethane from around $30 \%$ to $80 \%,{ }^{16}$ demonstrating the potential of sitespecific titration using amines for selectivity control.

Bingjun $\mathrm{Xu}$ and co-workers also reported the use of pyridine to improve methyl lactate 


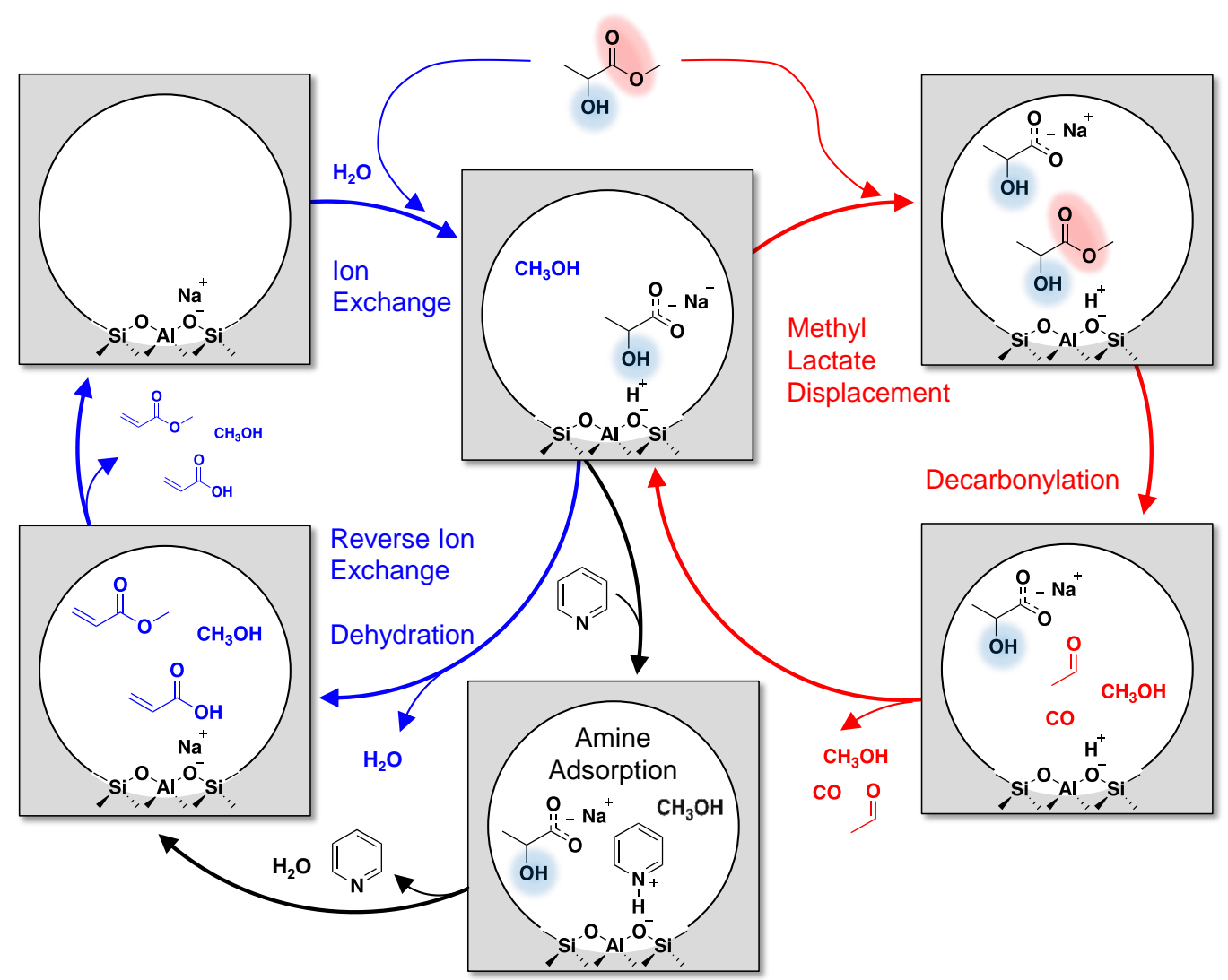

Scheme 1. Major reaction pathways in methyl lactate are dehydration and decbonylation with NaY catalyst and amine adsorbents. Methyl lactate dehydration yields acrylic acid, methanol and methyl acrylate and decarbonylation yields acetaldehyde, carbon monoxide and methanol. Both catalytic cycles are proposed to occur on in-situ generated Brønsted acid sites. Introduction of a Brønsted titrant such as pyridine has been proposed to suppress decarbonylation and increase dehydration selectivity to acrylates.

dehydration selectivity by $\sim 13 \mathrm{C} \%$ over sodiumexchanged zeolite $\mathrm{Y}(\mathrm{NaY}) .{ }^{17-19}$ While no Brønsted acidity is present in fully-exchanged $\mathrm{NaY}$ zeolite, Brønsted acid sites (BAS) can be generated during the reaction and are proposed to be the active sites for the major side reaction of decarbonylation. The reaction scheme based on the mechanism proposed by Murphy et al. ${ }^{17-19}$ is depicted in Scheme 1. Two major reaction pathways are shown: (i) dehydration (in blue) that involves the lactate hydroxyl group, and (ii) decarbonylation (in red) that occurs on the lactate carboxylate group. When methyl lactate approaches a sodium acid site on $\mathrm{NaY}$, ion exchange and subsequent hydrolysis yields sodium lactate, methanol, and a BAS (Supplementary Note 1 ). The presence of a sodium cation stabilizes the carboxylate group of sodium lactate via the formation of an ion pair. Therefore, sodium lactate is proposed to only undergo dehydration to sodium acrylate on the in situ generated BAS. Reverse ion exchange between sodium acrylate and the BAS then generates acrylic acid as the primary dehydration product and regenerates a sodium acid site for subsequent catalytic cycles. Acrylic acid can further react with methanol from the ion exchange step to form methyl acrylate as the secondary dehydration product.

The proposed decarbonylation cycle occurs when methyl lactate displaces sodium lactate on a BAS. As the carboxylate group on methyl lactate is not protected by a sodium cation, methyl lactate has been shown to only decarbonylate over BAS at elevated temperatures ${ }^{19}$. Decarbonylation produces byproducts of methanol, carbon monoxide, and acetaldehyde. The BAS can be re-occupied by a nearby sodium lactate or methyl lactate. Introduction of a non-reactive titrant, such as pyridine $^{17,18}$ that binds on BAS can suppress methyl lactate decarbonylation and improve dehydration selectivity. Decarbonylation suppression by 
Table 1. The Si/Al ratio and textural information of zeolite samples measured by ICP-OES and argon physisorption at $87 \mathrm{~K}$.

\begin{tabular}{lcc}
\hline Co-fed Amine & NaY (CBV-100) & HY (CBV-500) \\
\hline $\mathrm{Si} / \mathrm{Al}$ & 2.65 & 2.70 \\
Pore Diameter $[\AA]$ & 7.17 & 7.45 \\
Pore Volume $\left[\mathrm{cm}^{3} \mathrm{~g}^{-1}\right]$ & 0.440 & 0.286 \\
\hline
\end{tabular}

pyridine titration is due to the basic nitrogen of pyridine outcompeting the weaker oxygenated functional groups on methyl lactate, resulting in a higher BAS coverage by pyridine than methyl lactate.

By improving methyl lactate dehydration selectivity, the application of amine for in situ selectivity tuning also contributes to the current efforts in the industrialization of renewable acrylate production. Acrylic acid and acrylates are valuable monomers for commercial polymers in absorbents, coatings, paints, and adhesives with a market demand of eight megatons in 2017 at an annual growth rate of $4 \% .^{20,21}$ Currently, acrylic acid is produced via propylene oxidation as a downstream product of the petroleum industry. Lactic acid has been considered as a promising renewable feedstock to acrylic acid and desirable selectivity around $60-70 \mathrm{C} \%$ to acrylic acid has been achieved in gas phase dehydration over solid acid catalysts such as alkali-modified zeolites, hydroxyapatites, and phosphates. ${ }^{22-28}$ While lactic acid can be produced from sugar fermentation with greater than $90 \%$ yield, ${ }^{29}$ lactic acid tends to selfoligomerize under typical gas phase reaction temperature $\left(\sim 300{ }^{\circ} \mathrm{C}\right)$. However, a surrogate compound, methyl lactate, closely mimics the chemistry, preserving all major reaction pathways. Additionally, due to the low stability, lactic acid is generally converted to lactate esters in the purification process. ${ }^{30}$ Therefore, methyl lactate dehydration over $\mathrm{NaY}$ was selected as the probe reaction to explore the effect of titrant design for selectivity tuning in porous materials.

As current efforts in lactate conversion to acrylates focus on dehydration selectivity enhancement, further selectivity tuning may be feasible with amines that are more basic than pyridine. The hypothesis is that pyridine titrates BAS catalyzing decarbonylation owing to its higher basicity than methyl lactate. Increasing amine basicity by adding electron-donating alkyl substituent groups to increase electron density at the amine nitrogen should result in stronger BAS adsorption and side reaction suppression, leading to higher selectivity to methyl lactate dehydration. However, the size of amine molecules also increases with the addition of alkyl substituent groups. If the size of the amine molecule is comparable to the $\mathrm{NaY}$ pore diameter, steric interactions between the amine and the zeolite framework may limit BAS titration by amines.

In this work, we explored the effect of titrant basicity and steric limitations on methyl lactate dehydration to identify co-feed titrant modifiers that achieve higher dehydration selectivity (preferably above $90 \mathrm{C} \%$ ). The effect of amines on methyl lactate dehydration selectivity improvement was evaluated by co-feeding amines with different basicity and size over $\mathrm{NaY}$ catalyst. A dehydration selectivity maximum was observed with the size of the amines, indicating hindrance from steric limitations on further selectivity enhancement by amine basicity. Steric limitations in the form of internal diffusion limitations and local steric interactions were evaluated with both experiment and computation, leading to a conclusion that amines with high bascity and moderate size or steric limitations afford optimal selectivity control.

\subsection{Results and Discussion.}

2.1 Materials Characterization. Sodiumexchanged $\mathrm{NaY}$ and the proton form of zeolite $\mathrm{Y}$ (HY) were used to catalyze methyl lactate dehydration and study amine adsorption behavior in zeolite Y pores. The pore diameter and volume from argon physisorption for $\mathrm{NaY}$ and $\mathrm{HY}$ reported in Table 1 were consistent with reported values of comparable materials. ${ }^{19,31,32}$ The isotherms and Saito-Foley pore distributions for $\mathrm{NaY}$ and $\mathrm{HY}$ can be found in Figure S3 in Supplementary Note 3. Powder X-ray diffraction (XRD) patterns in Figure $\mathbf{S} 4$ of NaY and HY were consistent with the XRD patterns from the same materials in literature. ${ }^{17,33}$ Solid-state ${ }^{27}$ Al-MAS NMR indicated negligible presence of extra-framework aluminum in $\mathrm{NaY}$ (Figure S5). Inductively-coupled plasma - optical emission spectrometry (ICP-OES) results revealed the actual $\mathrm{Si} / \mathrm{Al}$ ratio to be 2.65 for $\mathrm{NaY}$ and 2.70 for HY. The reactive gas chromatography (RGC) method indicated only a small amount of Brønsted acidity in $\mathrm{NaY}\left(<29 \mu \mathrm{mol}\left(g_{c a t}\right)^{-1}\right)$, which was 


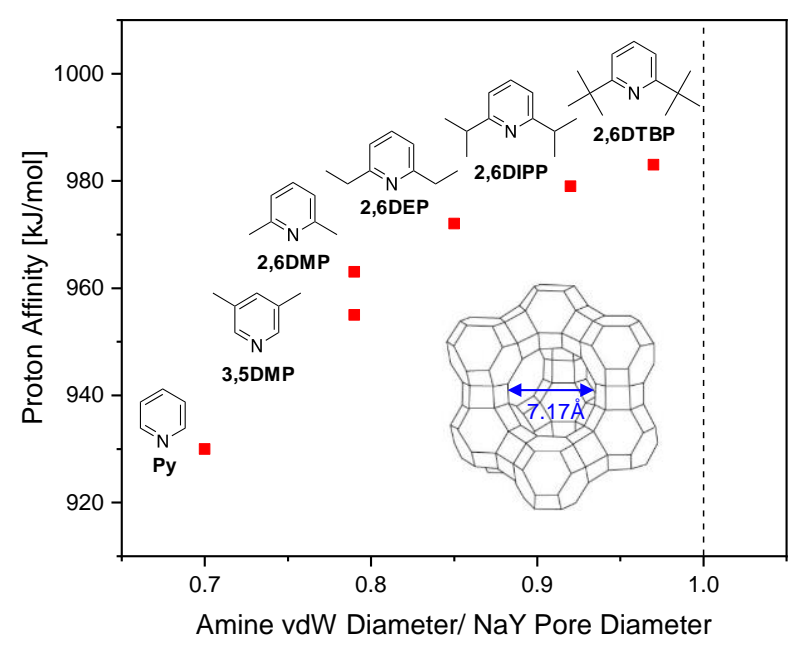

Figure 1. Proton affinity ${ }^{1}$ is reported over the nondimensionalized size of amines. The nondimensionalized size is calculated by normalizing the $\mathrm{vdW}$ diameter of amine by the pore diameter of $\mathrm{NaY}$. $\mathrm{vdW}$ diameter of amine is calculated with QSAR Toolbox, and the pore diameter of $\mathrm{NaY}$ is measured to be $7.17 \AA$ by Argon physisorption at $87 \mathrm{~K}$. Structure of a basic unit of Zeolite $\mathrm{Y}$ is obtained from Lutz et al. ${ }^{2}$ to show the pores in Zeolite Y.

further supported by the absence of methanol conversion on $\mathrm{NaY}$ for a wide range of temperatures from 150 to $300{ }^{\circ} \mathrm{C}$. The BAS density of HY was determined to be $1152 \mu \mathrm{mol} \mathrm{g}{ }^{-1}$ by in situ titration on methanol dehydration (Figure 8a) in section 2.5, in agreement with the same materials used by Murphy et. al. ${ }^{19}$. Details on BAS density measurements are presented in sections 4.2 and 4.3.3.

2.2 Selectivity Control of Amines and NaY Catalyst Stability. Amines with higher basicity than that of pyridine were selected for experimental evaluation, as characterized by the tabulated proton affinity values ${ }^{34}$ in Figure 1. Here, a more basic amine functionality is achieved by adding electrondonating alkyl substituent groups on pyridine. Amines with alkyl groups closer to the pyridine nitrogen exhibit higher basicity as shown by the proton affinity increase with methyl groups at the three and five positions on 3,5-dimethylpyridine (3,5DMP) to the two and six positions on 2,6dimethylpyridine (2,6DMP). While the proton affinity values of selected amines are above 930 $\mathrm{kJ} / \mathrm{mol}$, the proton affinity of methyl lactate is calculated to be $779 \mathrm{~kJ} / \mathrm{mol}$ at the methoxy oxygen using the method described in section 4.4.1. The stronger basicity of the amine compared with methyl lactate indicates that amine adsorption should be preferred over adsorption of methyl lactate by the methoxy oxygen on the BAS, therefore suppressing the decarbonylation pathway.

To identify potential steric limitations of titrant amines, the van der Waals diameter was selected as the method to quantify the size of amines, due to the more reasonable molecular size estimations for amines in this study compared with descriptors such as the 'effective diameter', 'maximum', and 'kinetic' diameter (Table S1 and Supplementary Note 5). The addition of alkyl substituent groups on pyridine to increase amine basicity also inevitably increases the size of amines (Figure 1). A basic unit of zeolite $\mathrm{Y}^{35}$ is also shown in Figure 1. The large central cavity is the 'supercage', which has a diameter of $11.2 \AA^{36} .^{\text {Connections of supercages }}$ form channels or pores in zeolite Y. The window size of the supercage determines pore size and has a diameter of $7.4 \AA$, ${ }^{36}$ which agrees with the $7.17 \AA$ $\mathrm{NaY}$ pore diameter measured by argon physisorption as shown in Table 1. A nondimensional amine size was then calculated by normalizing the calculated amine van der Waals diameters by the experimentally measured $\mathrm{NaY}$ pore or supercage window diameter. As the nondimensional molecular size approaches to a value of 1.0, steric hindrances appear due to the bulkiness of the amine and rigidity of both the zeolite framework and the pyridine ring. Even larger molecules will be sieved, preventing access to active sites in zeolite $\mathrm{Y}$ pores.

The effect of the amine on methyl lactate dehydration was first evaluated by co-feeding pyridine (Py), 3,5DMP, 2,6DMP, and 2,6diethylpyridine $(2,6 \mathrm{DEP})$ at a molar ratio of methyl lactate:amine of 10:1 over $\mathrm{NaY}$ catalyst. While conversion decreased from $90 \mathrm{C} \%$ without amine or $60 \mathrm{C} \%$ with amine to below $20 \mathrm{C} \%$ over time due to catalyst deactivation (Figure S8a), dehydration selectivity only varied by at most $2-3$ $\mathrm{C} \%$ over at least $50 \mathrm{~h}$ time-on-stream (TOS) (Figure S8c), which indicates that deactivation does not change the distribution of products in the methyl lactate reaction system. Therefore, it is possible to compare dehydration selectivity at different initial conversion values with or without amine using the time-averaged dehydration selectivity in Table 2.

At $300{ }^{\circ} \mathrm{C}$, methyl lactate dehydration selectivity was observed to increase by $12-19 \mathrm{C} \%$ 
Table 2. Reactivity of Methyl lactate over NaY with the addition of amines is reported at reaction condition of $300{ }^{\circ} \mathrm{C}, \mathrm{P}_{\text {total }}=101.3 \mathrm{kPa}\left(\mathrm{P}_{\text {methyl lactate }}=78.0 \mathrm{~Pa}, \mathrm{P}_{\text {amine }}=\right.$ $7.8 \mathrm{~Pa}, \mathrm{P}_{\text {water }}=1.1 \mathrm{kPa}$, balanced by $\mathrm{He}$ ), and WHSV = $0.9 \mathrm{~h}^{-1}$. Error bars are 95\% confidence intervals estimated from error propagation with methods in Supplementary Note 2.

\begin{tabular}{lccc}
\hline $\begin{array}{l}\text { Co-fed } \\
\text { Amine }\end{array}$ & $\begin{array}{c}\text { Proton } \\
\text { Affinity } \\
{[\mathbf{k J} / \mathbf{m o l}]}\end{array}$ & $\begin{array}{c}\text { Dehydration } \\
\text { Selectivity } \\
{[\mathbf{C} \%]}\end{array}$ & $\begin{array}{c}\text { Initial } \\
\text { Conversion } \\
{[\mathbf{C} \%]}\end{array}$ \\
\hline no amine & - & $61 \pm 1$ & $92 \pm 3$ \\
Py & 930 & $73 \pm 1$ & $55 \pm 2$ \\
3,5DMP & 955 & $76 \pm 1$ & $58 \pm 1$ \\
2,6DMP & 963 & $79 \pm 1$ & $64 \pm 2$ \\
2,6DEP & 972 & $80 \pm 2$ & $64 \pm 3$ \\
\hline
\end{tabular}

with the addition of these amines at initial conversion in the range of 55 to $92 \mathrm{C} \%$. The $12 \mathrm{C}$ $\%$ increase in dehydration selectivity with pyridine was consistent with the results from Murphy et al. ${ }^{17-19}$ Higher dehydration selectivity was measured for amines with higher basicity than pyridine. The productivity of acetaldehyde, a byproduct from the decarbonylation pathway, was suppressed to almost zero with the introduction of amines (Figure 2), indicating that improvement in dehydration selectivity was due to suppression on the major side reaction, methyl lactate decarbonylation. As illustrated in Scheme 1, suppression on the decarbonylation pathway was achieved by amine titration on the BAS under competitive adsorption against methyl lactate. Therefore, the ability to titrate in situ generated BAS is crucial in methyl lactate dehydration selectivity control.

The enhancement in dehydration selectivity and catalyst stability with the considered amines prompted investigation into the further dehydration selectivity increases with amines of even higher basicity than 2,6DEP. However, experiments with additional amines demonstrated the limitation of this approach; dehydration selectivity decreased as amine basicity and size was further increased (Figure 3a). In addition, the data of Figure 3b revealed that dehydration selectivity maximized over the size of amines. If amine basicity is the dominant factor that controls BAS titration and side

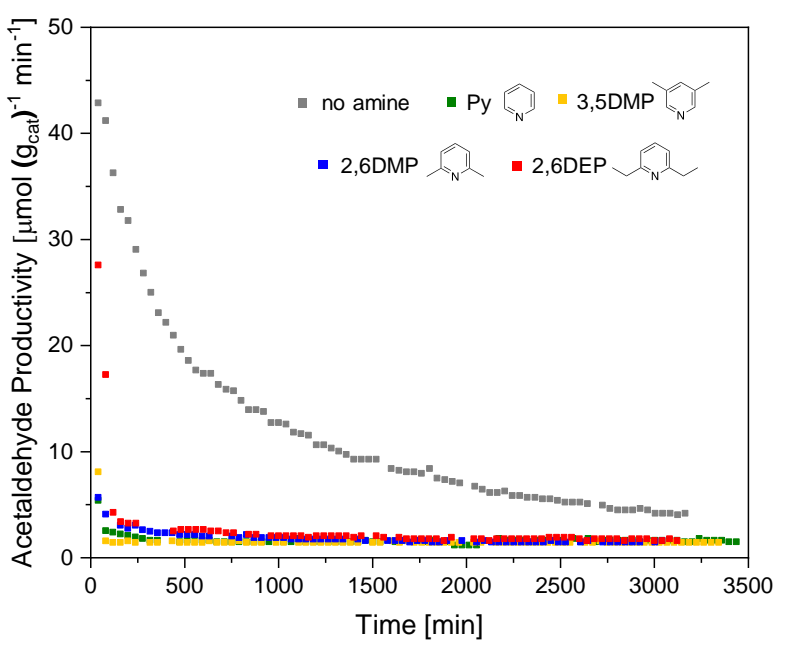

Figure 2. Acetaldehyde productivity as a function of time-on-stream (TOS) with the addition of amines. Reaction condition: $\mathrm{NaY}, 300{ }^{\circ} \mathrm{C}, \mathrm{P}_{\text {total }}=101.3 \mathrm{kPa}$ $\left(\mathrm{P}_{\text {methyl lactate }}=78.0 \mathrm{~Pa}, \mathrm{P}_{\text {amine }}=7.8 \mathrm{~Pa}, \mathrm{P}_{\text {water }}=1.1 \mathrm{kPa}\right.$, balanced by He at a flowrate of $\left.90 \mathrm{~mL} \mathrm{~min}^{-1}\right)$, WHSV = $0.9 \mathrm{~h}^{-1}$.

reaction suppression, dehydration selectivity should increase monotonically with amine basicity, as shown with the four amines in Table 2 . The dehydration selectivity maximum indicates that a transition occurs as the size of titrant approaches to around $\sim 85 \%$ of the $\mathrm{NaY}$ pore diameter, after which amine steric effects begin to limit amine binding on BAS. For this reason, understanding amine spatial access to BAS in HY zeolite is crucial for the prediction of an optimal titrant with balanced basicity and geometric properties for methyl lactate dehydration selectivity control.

2.3 Factors Controlling BAS Titration by Amines. Based on the dehydration selectivity maximum in Figure 3, we propose three factors that control the effectiveness of in situ BAS titration by amines as depicted in Scheme 2: (a) internal diffusion limitations due to the bulky overall size of the titrant molecule; (b) local steric limitations for the kinetics of competitive adsorption on BAS; (c) and binding strength on the BAS.

While external BAS on the outer surface of zeolites are in general accessible to both reactants and titrants regardless of their overall size, accessing BAS in zeolite pores requires molecules to diffuse through zeolite pores. Therefore, the first limitation for amine titration is internal diffusion, which is governed by the overall size of amine. In the case of faujasite zeolites such as $\mathrm{NaY}$, amines 
(a)

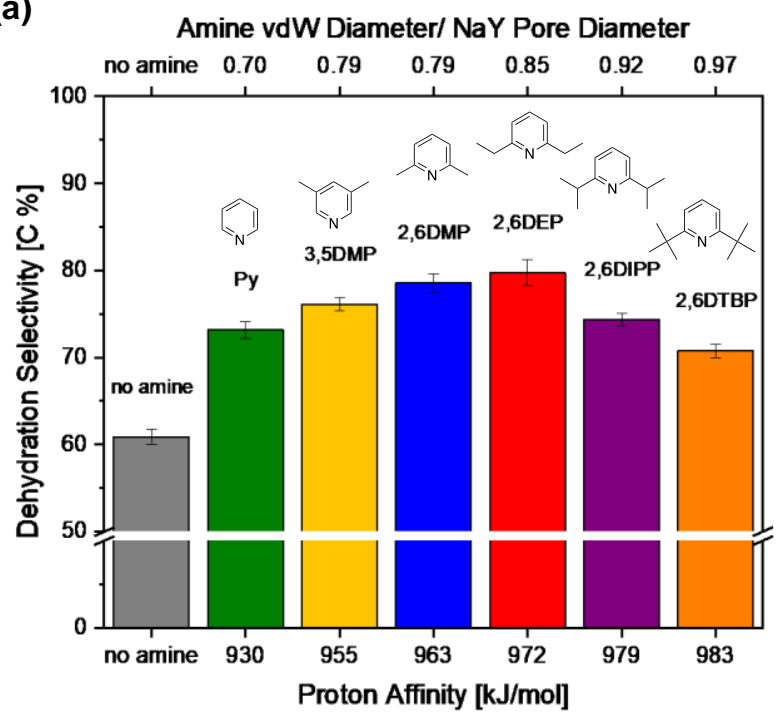

(b)

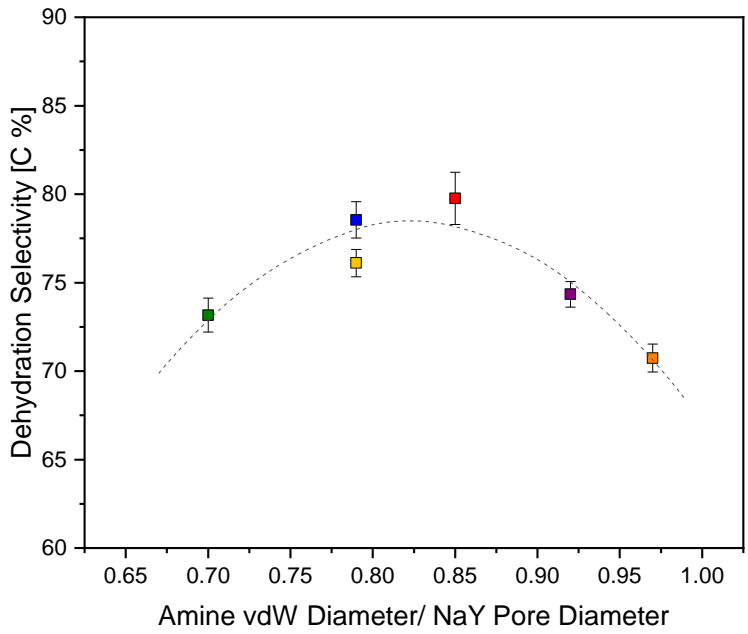

Figure 3. (a) Dehydration selectivity of methyl lactate over $\mathrm{NaY}$ with the addition of amines of various proton affinity and size. (b) Dehydration selectivity over size are shown at reaction condition of $300{ }^{\circ} \mathrm{C}, \mathrm{P}_{\text {total }}=101.3 \mathrm{kPa}\left(\mathrm{P}_{\text {methyl lactate }}\right.$ $=78.0 \mathrm{~Pa}, \mathrm{P}_{\text {amine }}=7.8 \mathrm{~Pa}, \mathrm{P}_{\text {water }}=1.1 \mathrm{kPa}$, balanced by helium at a flowrate of $90 \mathrm{~mL} \mathrm{~min}^{-1}$ ), and WHSV $=0.9 \mathrm{~h}^{-1}$. The error bars are $95 \%$ confidence intervals calculated from error propagation. Error bars are $95 \%$ confidence intervals estimated from error propagation with methods in Supplementary Note 2. Dotted curve is provided to guide the eye.

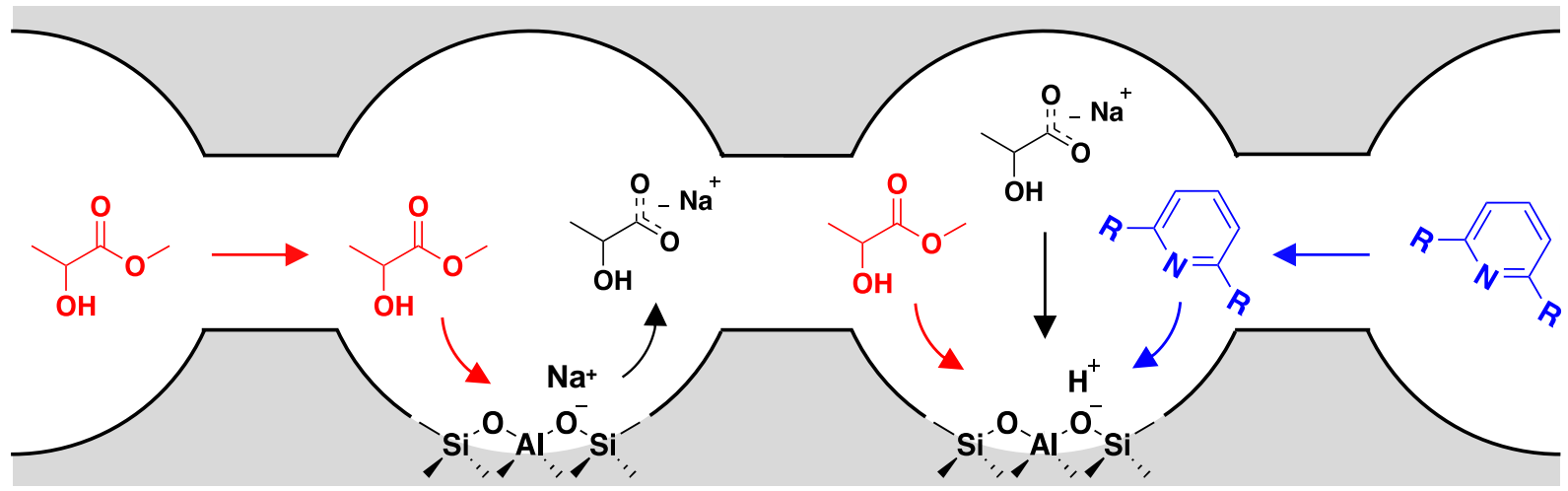

Scheme 2. Proposed steps in the titration of in-situ generated Brønsted acid sites by amines: (a) amine transport to a BAS via internal diffusion controlled by internal diffusion limitation; (b) competitive adsorption against methyl lactate governed by local steric limitations; and (c) desorption from BAS determined by amine basicity and local steric limitations.

with a larger overall size and a higher degree of overall steric hindrance may pass through the windows between supercages and diffuse slower in zeolite pores. Methyl lactate, due to its smaller size, may readily access BAS faster than bulky amines. At the beginning of co-feed experiments, methyl lactate displacement can occur before bulky amines can access BAS due to internal diffusion limitations, resulting in ineffective BAS titration. However, internal diffusion limitations may be overcome by allowing enough time for the bulky amine to diffuse through $\mathrm{NaY}$ pores. One solution is to pre-saturate the catalyst bed with amine prior to feeding methyl lactate, as discussed in Section 2.4.

Once the amine approaches a BAS, it undergoes competitive adsorption with methyl lactate on the BAS. This step is controlled by the local steric interactions between the adsorbate molecule and the zeolite framework around the BAS. We define steric van der Waals interactions as including steric repulsion (steric destabilization) 


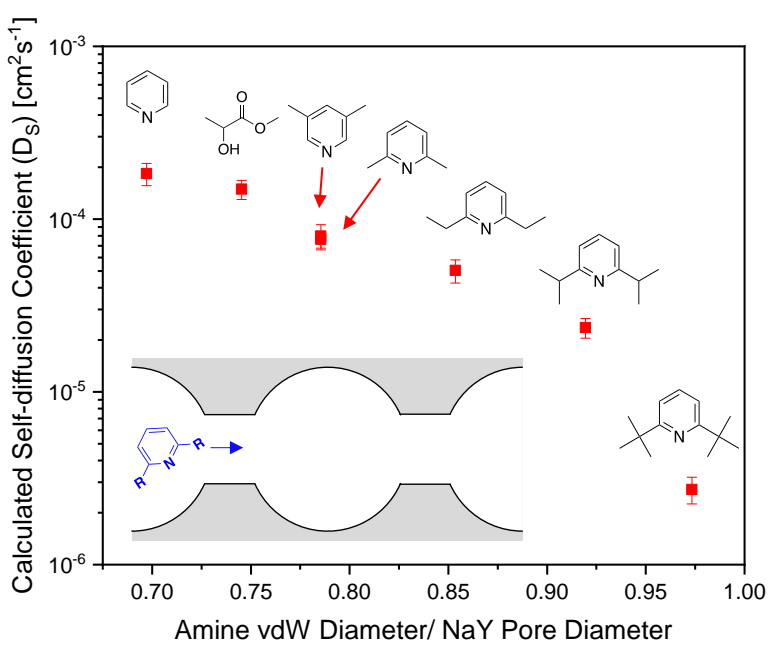

Figure 4. Self-diffusion coefficient, $D_{S}$, over the nondimensionalized size of methyl lactate and amines at 300 ${ }^{\circ} \mathrm{C}$ in siliceous zeolite $\mathrm{Y}$ were calculated by molecular dynamics simulations with the PCFF+ forcefield. Error bars are $95 \%$ confidence intervals estimated from 20 independent runs.

and the steric stabilization from the zeolite ${ }^{5,15,37}$ As amines approach a BAS, proton transfer between the site and amine would yield an ion pair between the protonated amine and the deprotonated zeolite, which stabilizes the protonated amine via electrostatic stabilization. ${ }^{5}$ When steric repulsion from large substituent groups such as the tert-butyl groups in 2,6DTBP is significant, adsorption is expected to be less favorable. Further quantification of amine local steric limitations is described with computation and experiment in Section 2.5.

Upon adsorption on a BAS, the tendency for desorption depends on the binding strength of the amine. Binding strength is governed by both basicity and local steric limitations of the adsorbate molecule. While basicity determines the affinity to the Brønsted proton, local steric limitations determine how close an adsorbate can approach a BAS. Based on the selectivity maximum in Figure 3, a lower binding strength may be observed with bulky amines such as 2,6DIPP and 2,6DTBP, which will be examined by computation in Section 2.5. These bulky amines may tend to desorb more easily from the BAS. The open site is then free to adsorption and reaction of methyl lactate, which leads to side reactions and a reduction in dehydration selectivity. The hypotheses on internal diffusion limitations and local steric limitations will be addressed in the following two sections.

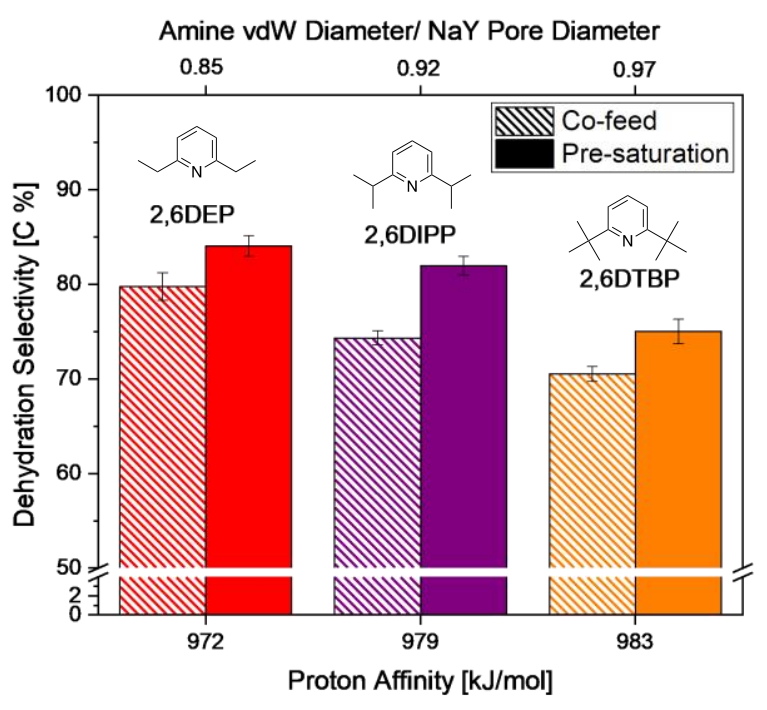

Figure 5. Methyl lactate dehydration selectivity under pre-saturate condition is comparison with the value from co-feed condition with the addition of 2,6DEP, 2,6DIPP, and 2,6DTBP. Reactivity measurements were performed at $300{ }^{\circ} \mathrm{C}$ over $\mathrm{NaY}, \mathrm{P}_{\text {total }}=101.3 \mathrm{kPa}\left(\mathrm{P}_{\text {methyl lactate }}=78.0\right.$ $\mathrm{Pa}, \mathrm{P}_{\text {amine }}=7.8 \mathrm{~Pa}, \mathrm{P}_{\text {water }}=1.1 \mathrm{kPa}$, balanced by $\left.\mathrm{He}\right)$, and $\mathrm{WHSV}=0.9 \mathrm{~h}^{-1}$. Error bars are $95 \%$ confidence intervals estimated from error propagation with methods in Supplementary Note 2 .

2.4 Internal Diffusion Limitations of Amines. One of the potential limiting factors for effective BAS titration is internal diffusion which becomes more hindered with larger amines. Molecular dynamics (MD) simulations characterized the speed of amine diffusion through pores in zeolite $\mathrm{Y}$ at $300^{\circ} \mathrm{C}$; details on amine diffusion simulations are presented in Supplementary Note 7. As shown in Figure 4, the self-diffusion coefficient of amines decreases with an increase in size. While pyridine diffuses at a similar rate as methyl lactate, 3,5DMP, 2,6DMP, and 2,6DEP diffuse two-to-three times slower. Even bulkier amines, namely 2,6DIPP and 2,6DTBP, diffuse one and two orders of magnitude slower, respectively, than methyl lactate in zeolite Y. The significantly slower diffusion compared with methyl lactate may hinder the effectiveness of BAS binding and selectivity control by bulky amines such as 2,6DIPP and 2,6DTBP due to internal diffusion limitations.

The effect of internal diffusion limitations on methyl lactate selectivity enhancement was probed with experiment by first pre-saturating $\mathrm{NaY}$ with flowing amine through the catalyst bed for 24 hours, which likely ensured sufficient time for 
bulky amines such as 2,6DIPP and 2,6DTBP to diffuse through $\mathrm{NaY}$ pores. After the pre-saturation treatment, methyl lactate and amine were co-fed to $\mathrm{NaY}$ at $300{ }^{\circ} \mathrm{C}$ with the same weight hourly space velocity (WHSV) and molar ratio used in the previous co-feed experiment in Section 2.2. Cofeeding amine was necessary to ensure that the catalyst bed was not deprived of titrant molecules in any supercages during the experiment. Presaturating the catalyst bed with bulky amines (i.e., 2,6DEP, 2,6DIPP, and 2,6DTBP) was observed to significantly improve methyl lactate dehydration selectivity by 5-8 C \%, as shown in Figure 5. The TOS dehydration selectivity, conversion, and product distribution under co-feed and presaturation conditions were compared in Figure S15 for 2,6DEP, 2,6DIPP, and 2,6DTBP. Under co-feed conditions, dehydration selectivity started below 70 $\mathrm{C} \%$ and increased over time in the first two hours TOS and stabilized at the reported averaged selectivity in Figure 5. Afterward, while under presaturation conditions, dehydration selectivity was relatively stable throughout the experiment (Figure S15a, e, and i). Additionally, selectivity to decarbonylation products including $\mathrm{CO}_{x}$ and acetaldehyde were initially at higher values and stabilized at lower values after the first two hours TOS, but they remained relatively stable under presaturation conditions throughout the experiments (Figure S15c, d, g, h, k, and l). The induction periods observed in product distribution under cofeed conditions indicate that sufficient time is required for steady decarbonylation suppression by bulky amines. The result supports the hypothesized limitation that BAS titration by bulky amines is hindered by internal diffusion, or at least by amine movement within the porous zeolite catalyst. By allowing sufficient time for the bulky amines to access all cavities within the catalyst, the effect of internal diffusion limitations was likely reduced.

A dehydration selectivity as high as $84 \mathrm{C} \%$ was experimentally measured with 2,6DEP under the pre-saturation condition, which is an improvement of $23 \mathrm{C} \%$ from the dehydration selectivity obtained over NaY without amine (Figure 5) and is higher than the $13 \%$ enhancement achieved by Murphy et al. using pyridine as the titrant. ${ }^{17,18}$ The $84 \mathrm{C} \%$ dehydration selectivity achieved is also higher than the $60-75 \mathrm{C} \%$ selectivity achieved with modified $\mathrm{NaY}$ by impregnating phosphates ${ }^{38,39}$ or tuning zeolite acid strength using ion-exchange with metal

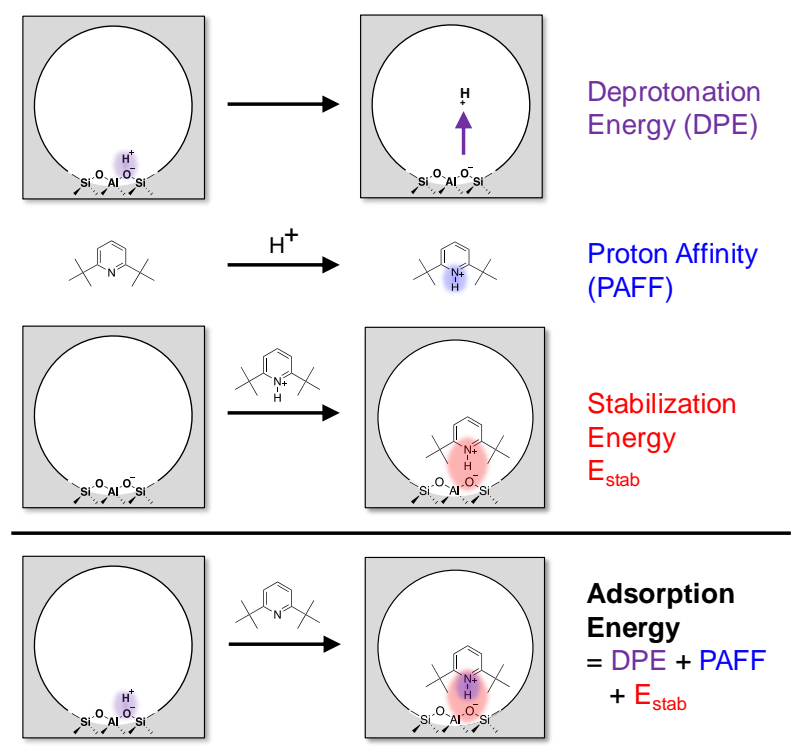

Scheme 3. Amine adsorption on a BAS can be separated into three steps: zeolite deprotonation, amine protonation and zeolite stabilization. The change in energy due to amine adsorption on a BAS, the adsorption energy, can be calculated as the summation of deprotonation energy, proton affinity, and stabilization energy.

cations. ${ }^{40-42}$ An even higher selectivity of $\sim 80 \%$ or even $84 \%$ can be achieved with alkali-modified ZSM-5, ${ }^{22,24,43}$ but ZSM-5 has a smaller pore size compared with zeolite $\mathrm{Y}$ and is beyond the scope of this paper. Interestingly, the dehydration selectivity with 2,6DIPP under pre-saturation condition increased by $8 \mathrm{C} \%$ compared with the value under co-feed condition, but the improvement in dehydration selectivity with 2,6DTBP is not as apparent as that with 2,6DIPP. This observation indicates the existence of an additional factor that controls BAS titration by 2,6DTBP, which we attribute to the local steric limitations from the steric interactions between amine and the zeolite wall around the BAS.

2.5 Local Steric Limitations of Amines. In addition to internal diffusion, effective binding of titrant amines to BAS can also be limited by local steric limitations, As stated in previous studies of BAS adsorption, ${ }^{5,44,45}$ the amine adsorption process can be decomposed into three independent steps: (i) zeolite deprotonation, (ii) amine protonation, and (iii) the stabilization due to the interaction between the protonated amine and the deprotonated zeolite. Similarly, the adsorption energy as calculated by DFT can be decomposed into three parts: the 
(a)

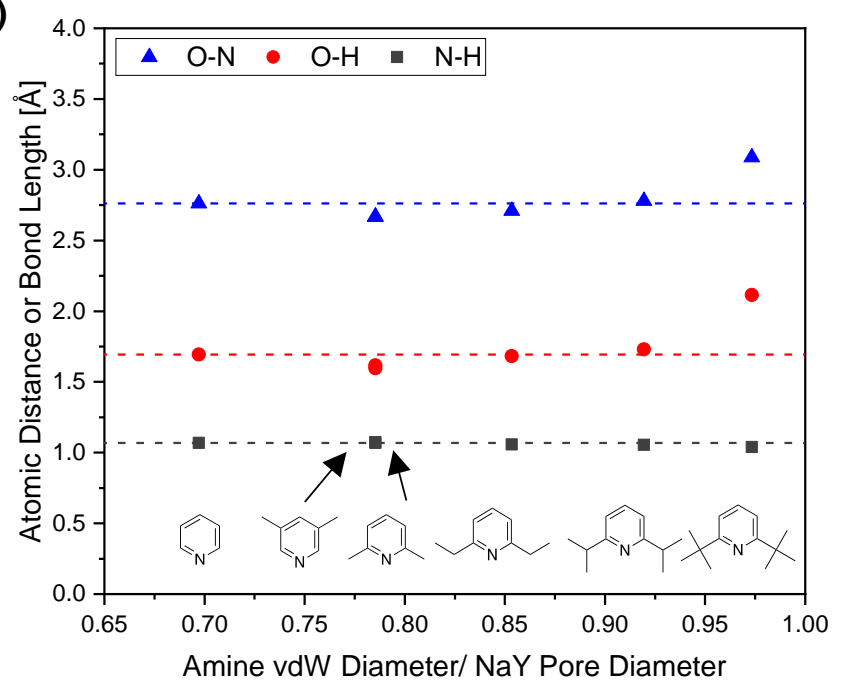

(b)

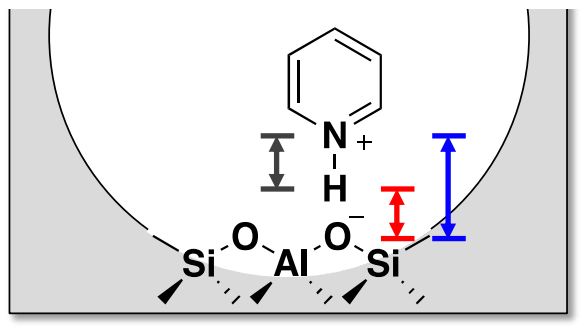

(c)

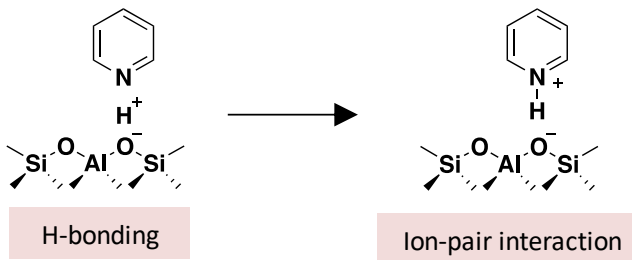

Figure 6. (a) Atomic distances or bond lengths as shown in (b) in the optimized amine zeolite $\mathrm{Y}$ adsorption structures are compared with dash lines of corresponding the calculated atomic distances in the pyridine-zeolite $\mathrm{Y}$ optimized structure. (c) proton transfer from zeolite to amine forms an in-pair interaction structure from the $\mathrm{H}-$ bonding structure.

deprotonation energy of the zeolite, proton affinity of amine, and the stabilization energy (Scheme 3). The electronic adsorption energy is calculated from the energy difference between the final optimized adsorbed structure $\left(E_{A Z}\right)$ and the initial structures of amine $\left(E_{A}\right)$ and the empty zeolite $\left(E_{Z}\right)$ at their fully relaxed states as shown in Equation (1).

$$
\text { Adsorption Energy }=E_{A Z}-\left(E_{A}+E_{Z}\right)
$$

The deprotonation energy (DPE) of zeolite Y was calculated to be $1200 \mathrm{~kJ} / \mathrm{mol}$ by Jones et al. ${ }^{46}$ The proton affinity (PAFF) values for amines were experimentally measured by Hunter et al. ${ }^{34}$ Therefore, stabilization energy $\left(E_{\text {stab }}\right)$ is calculated by Equation (2).

$$
E_{\text {stab }}=B E-D P E-P A F F
$$

The final optimized structure of the amine in the zeolite is expected to be successfully transformed from a hydrogen-bonded structure to an ion-pair interaction structure via proton transfer (Figure 6c). The calculated pyridine-zeolite $\mathrm{Y}$ adsorption structures were in agreement with previous work by Castella-Ventura et al. using density functional theory at the B3LYP/6-31+G* level, ${ }^{47}$ further supporting that a complete proton transfer from the zeolite to pyridine in occurring in our calculations.
All optimized amine-zeolite Y structures form ion-pair interactions, as expected for amine adsorption on a BAS on zeolite, but the nature of that interaction can be affected by the size of the amine. In general, the distances between $\mathrm{N}-\mathrm{H}, \mathrm{O}-\mathrm{H}$, and $\mathrm{O}-\mathrm{N}$ in the optimized amine-zeolite $\mathrm{Y}$ structures are similar to the values in our calculated pyridine-zeolite $\mathrm{Y}$ ion-pair interaction structure (Figure 6a and 6b), consistent with the formation of ion-pairs for all amines with the exception of 2,6DTBP. The N-H distance in 2,6DTBP - zeolite $\mathrm{Y}$ is $1.1 \AA$, indicating the formation of a $\mathrm{N}-\mathrm{H}$ bond, but the $\mathrm{O}-\mathrm{N}$ and $\mathrm{O}-\mathrm{H}$ distances are longer compared to the other amines, suggesting that a complete proton transfer has occurred resulting in the generation of a 2,6-ditertbutylpyridinium cation that has moved further away from the zeolite wall. The O-H distance is still below $2.5 \AA$, suggesting that a hydrogen bonding interaction could still be present, ${ }^{48}$ as in all other amine-zeolite optimized structures, but it is expected to be weaker due to the longer distance from the negative oxygen on the zeolite framework. Therefore, all optimized aminezeolite Y structures were in the ion-pair interaction mode, as expected for amine adsorption on a BAS on zeolite.

The electronic energy contributions to BAS adsorption with different amines can be described using Equations (1) and (2). While the adsorption 


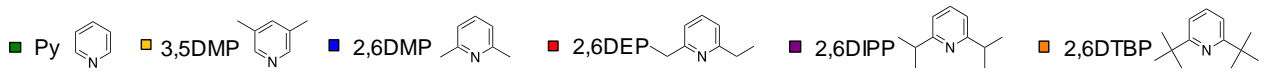

(a)

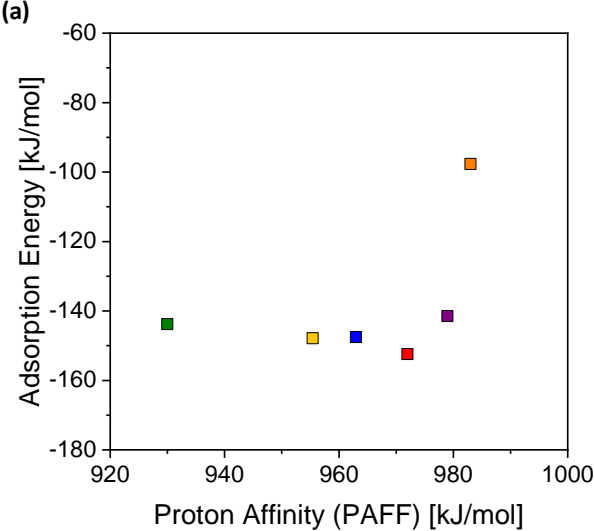

(c)

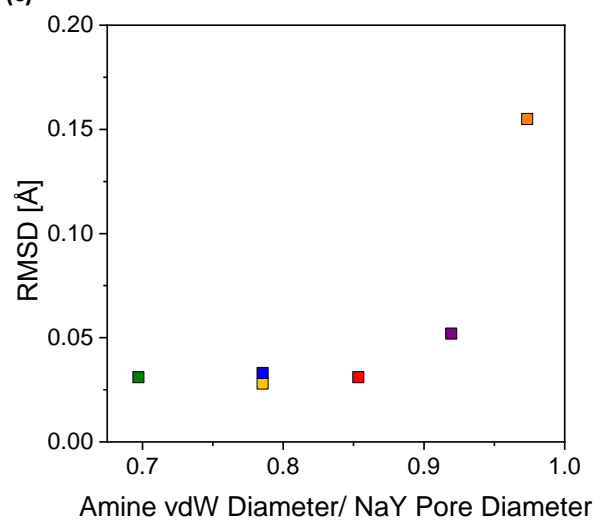

(b)

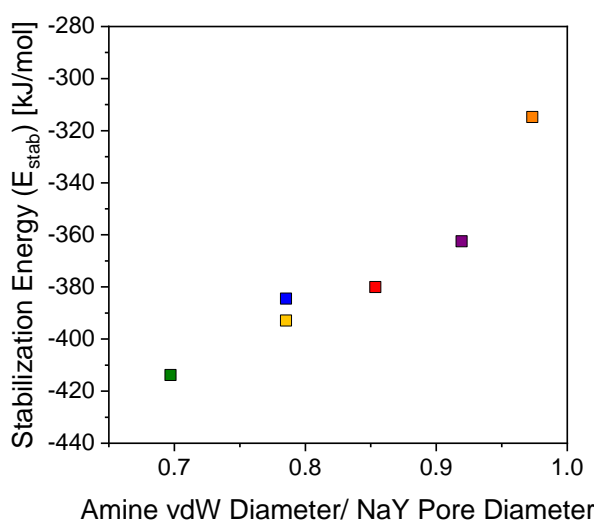

(d)

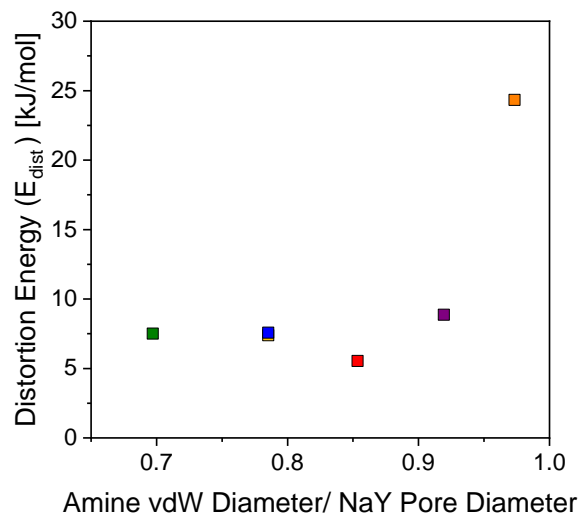

Figure 7. Energy components in amine adsorption on zeolite $\mathrm{Y}$ are reported as (a) Calculated PBE-D3 adsorption energy over proton affinity (PAFF) of amine; (b) calculated stabilization energy ( $\left.\mathrm{E}_{\mathrm{stab}}\right)$, (c) root mean square displacement $(\mathrm{RMSD})$, and $(\mathbf{d})$ calculated distortion energy $\left(\mathrm{E}_{\mathrm{dist}}\right)$ versus amine size.

energy increased from $-144 \mathrm{~kJ} / \mathrm{mol}$ with pyridine adsorption to around $-150 \mathrm{~kJ} / \mathrm{mol}$ with the adsorption of more basic amines, the bulkiest amine, 2,6DTBP, exhibited a significantly weaker adsorption energy of $-98 \mathrm{~kJ} / \mathrm{mol}$ (Figure 7a). The significantly weaker binding strength is consistent with the larger distance from the zeolite wall and the low selectivity enhancement observed with 2,6DTBP under both co-feed and pre-saturation conditions as shown in Figure 3a and Figure 5. We decompose the adsorption energy into three contributions: proton affinity, deprotonation energy, and stabilization energy. Proton affinity is a property of each amine, while deprotonation energy is a property of zeolite $\mathrm{Y}$ and can be assumed identical for all the amine-zeolite $\mathrm{Y}$ pairs. When binding strength is dominated by amine basicity, the adsorption energy, a negative value if adsorption is favorable, is observed to decrease with an increase in proton affinity for smaller amines such as pyridine, 3,5DMP, 2,6DMP, and 2,6DEP as shown in Figure 7a. However, lower binding strength is observed with bulky amines such as 2,6DTBP. The binding strength for 2,6DTBP, specifically, is $60 \mathrm{~kJ} / \mathrm{mol}$ weaker than those of the smaller and less basic amines in this study, showing that adsorption of 2,6DTBP is significantly less favorable compared with smaller amines.

The cause for the decrease in binding strength of 2,6DTBP can be found in the decrease in zeolite stabilization with the increase in amine size (Figure 7b). Stabilization energy, a negative value when zeolite stabilization dominates over repulsion, increases by approximately $5-20 \mathrm{~kJ} / \mathrm{mol}$ increments from pyridine, to $3,5 \mathrm{DMP}, 2,6 \mathrm{DMP}, 2,6 \mathrm{DEP}$, and to $2,6 \mathrm{DIPP}$, but jumps by $50 \mathrm{~kJ} / \mathrm{mol}$ from 2,6DIPP to $2,6 \mathrm{DTBP}$. The sudden increase in stabilization 

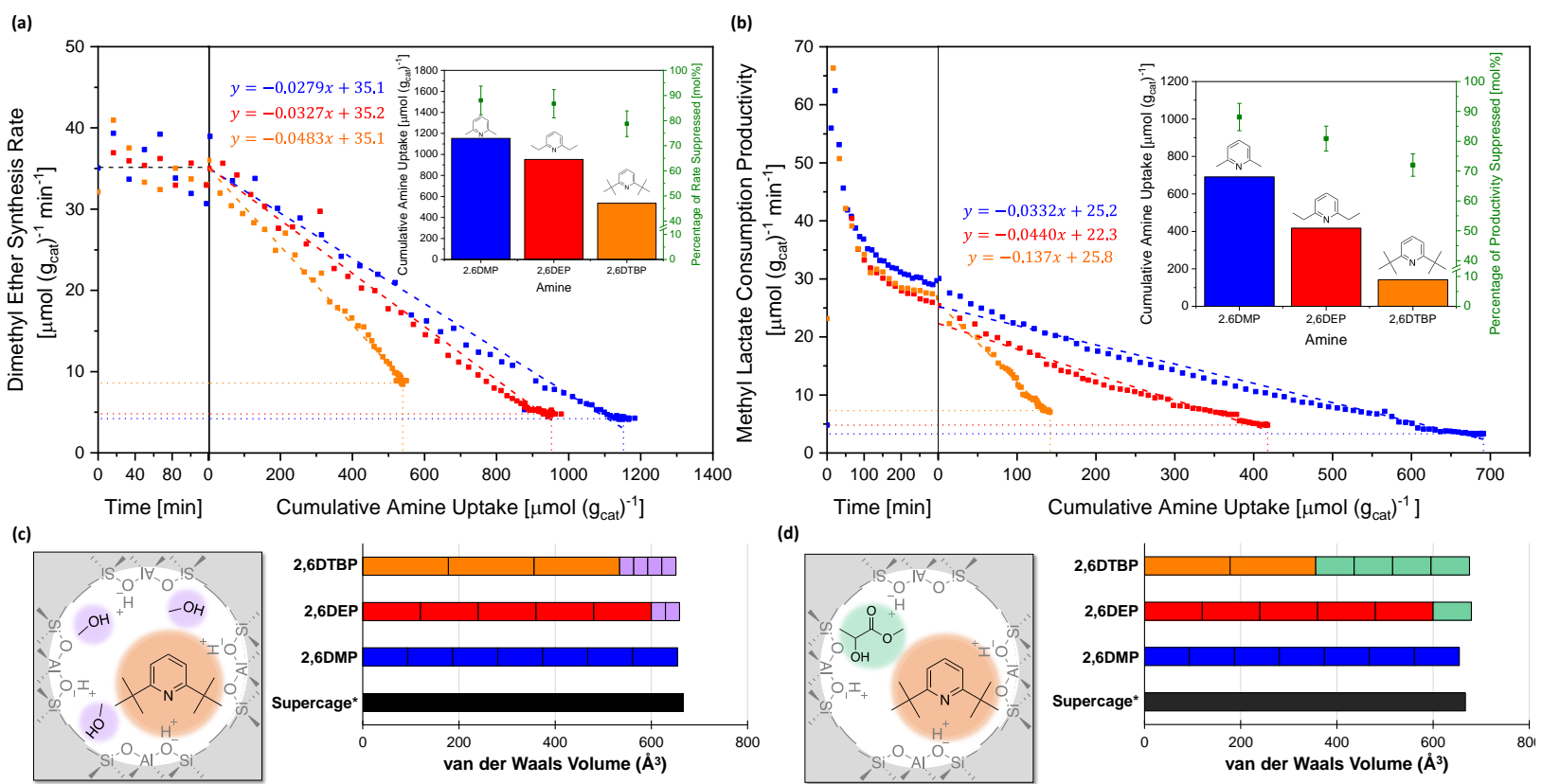

Figure 8. (a) Dimethyl ether synthesis rate and (b) methyl lactate consumption productivity over $\mathrm{HY}(\mathrm{Si} / \mathrm{Al}=2.55)$ are plotted as a function of time before amine introduction, and as a function of cumulative amine uptake after amine introduction. Data with 2,6DMP, 2,6DEP, 2,6DTBP are shown in blue, red, and orange respectively. The rate and productivity curves were fitted to linear relationships (dashed lines) against cumulative amine uptake, with equations shown above the curves. Cumulative amine uptake and percentage of productivity suppressed by each amine are shown in the bar chart. The number of amines that can fit in zeolite $Y$ framework within a $1000 \AA^{3}$ cube in the presence of (c) methanol (in purple) and (d) methyl lactate (in green) is estimated from the van der Waals volume of molecules and volume of supercage. Reaction condition for methanol dehydration: $150^{\circ} \mathrm{C}, \mathrm{P}_{\text {total }}=101.3 \mathrm{kPa}\left(\mathrm{P}_{\text {methanol }}=1 \mathrm{kPa}\right.$, $\mathrm{P}_{\text {amine }}=2 \mathrm{~Pa}$ after amine introduction, balanced by He), WHSV $=0.9 \mathrm{~h}^{-1}$. Reaction condition for methyl lactate decarbonylation: $453 \mathrm{~K}, \mathrm{P}_{\text {total }}=101.3 \mathrm{kPa}\left(\mathrm{P}_{\text {methyl lactate }}=78.0 \mathrm{~Pa}, \mathrm{P}_{\text {amine }}=0.3 \mathrm{~Pa}\right.$ after amine introduction, $\mathrm{P}_{\text {water }}=1.1$ $\mathrm{kPa}$, balanced by He), WHSV $=0.9 \mathrm{~h}^{-1}$. Error bars are $95 \%$ confidence intervals originated from the errors in rate or productivity measurements.

energy and adsorption energy observed with $2,6 \mathrm{DTBP}$ is likely due to steric repulsion from the supercage wall, and weaker hydrogen bonding interaction, which can also be indicated by the significantly longer distance between 2,6DTBP and the zeolite oxygen as shown in Figure 6a.

In addition to moving further away from the zeolite wall, bulky amines also undergo structural change from their fully relaxed structures in order to be accommodated in the constrained zeolite voids. The structural change can be quantified by the Root Mean Squared Deviation (RMSD) with respect to the relaxed state of the amine optimized in the gas phase. The RMSD of 2,6DTBP is threeto-five times higher than the RMSD values of smaller amines, indicating that 2,6DTBP undergoes the highest degree of structural change to adsorb on BAS among all selected amines (Figure 7c).
Due to structural changes, an increase in energy is expected from the amine in the fully relaxed state $\left(E_{A}\right)$ to adsorbed state $\left(E_{A_{-} a d s}\right)$ as shown in Equation (3)

$$
\text { Distortion Energy }=E_{A_{-} a d s}-E_{A}
$$

Consistent with the RMSD, the distortion energy for amines smaller than 2,6DTBP are similar and below $10 \mathrm{~kJ} / \mathrm{mol}$, while the distortion energy of $2,6 \mathrm{DTBP}$ is $24 \mathrm{~kJ} / \mathrm{mol}$, indicating a significantly larger structural change is required to form the ionpair structure even at a larger distance from the zeolite wall (Figure 7d). DFT calculations for amine adsorption on zeolite $\mathrm{Y}$ provide insight into the impact of local steric limitations on the binding strength of amines. Local steric constraints destabilize amine binding by reducing the zeolite 


\section{Chem Rxiv}

stabilization energy and forcing amines to undergo unfavorable structural changes to fit into the zeolite void near the BAS.

Accessibility of BAS by amines can also be evaluated by in situ titration using methanol dehydration as the probe reaction. Methanol was introduced to $\mathrm{HY}$ at $150{ }^{\circ} \mathrm{C}$ with a steady dehydration rate to dimethyl ether at 35 $\operatorname{\mu mol}\left(g_{\text {cat }}\right)^{-1} \mathrm{~min}^{-1}$ before a steady stream of 2,6DMP, 2,6DEP, or 2,6DTBP was introduced to titrate accessible BAS until saturation, identified when the dimethyl ether synthesis rate only fluctuated within $0.1 \%$ for 1 hour (Figure 8a). The measured cumulative amine uptake is 1152 $\mu \mathrm{mol}\left(g_{\text {cat }}\right)^{-1}$ for 2,6DMP, consistent with the BAS density of $1112 \mu \mathrm{mol}\left(g_{c a t}\right)^{-1}$ measured by Murphy et al. ${ }^{19}$ The cumulative amine uptake values are 952 and $535 \mu \mathrm{mol}\left(g_{\text {cat }}\right)^{-1}$, respectively, for 2,6DEP and 2,6DTBP showing that BAS accessibility is more limited for the bulky 2,6DTBP compared with smaller amines including 2,6DMP. Additionally, the percentage of rate suppressed is calculated to be $88 \%, 87 \%$, and $79 \%$, respectively, for 2,6DMP, 2,6DEP, and 2,6DTBP by Equation (4).

$$
\begin{aligned}
& \text { Percentage of rate suppressed }= \\
& 1-\frac{\text { rate at saturation }}{\text { rate at steady state before titration }}
\end{aligned}
$$

The residual rate observed is potentially due to sites that are accessible to small methanol molecules but not to the bulkier amines. ${ }^{15}$

While DFT calculations and in situ titration of methanol dehydration probed the local steric limitations on BAS adsorption by amines, neither studies considered the effect of methyl lactate and water on amine adsorption (both present during the methyl lactate dehydration reaction). The adsorption energies of methyl lactate by the methoxy oxygen and water at the BAS are calculated to be -40 and $-77 \mathrm{~kJ} / \mathrm{mol}$, respectively, which are significant when compared with the adsorption energy of 2,6DTBP $(97.7 \mathrm{~kJ} / \mathrm{mol})$.

To account for the impact of methyl lactate and water on amine adsorption, in situ titration experiments were conducted to reveal BAS accessibility by amines in the same environment enriched in methyl lactate and water as in the cofeed experiments (Figure 8b). The same $30 \mathrm{wt} \%$ methyl lactate aqueous solution as used in co-feed experiments was vaporized and introduced to $\mathrm{HY}$ at $180^{\circ} \mathrm{C}$, where only decarbonylation occurred. The detailed experimental procedure is presented in section 4.3.3. When conversion stabilized within $\sim 1 \%$ over one hour, a steady stream of 2,6DMP, $2,6 \mathrm{DEP}$, or 2,6DTBP was introduced to titrate BAS until saturation (Figure 8b). The cumulative amine uptakes were 691,417 , and $136 \mu \mathrm{mol}\left(g_{\text {cat }}\right)^{-1}$ for 2,6DMP, 2,6DEP, and 2,6DTBP, respectively. The discrepancy in 2,6DMP uptake between in situ titration experiments with methanol and methyl lactate arose from catalyst deactivation as indicated by the $\sim 50 \%$ decrease in methyl lactate consumption productivity before steady conversion in the left panel of Figure $\mathbf{8 b}$.

In the in situ amine titration experiments of Figure 8b, the three-fold lower cumulative uptake for 2,6DTBP compared with that of 2,6DEP shows that the BAS accessibility is significantly limited for 2,6DTBP than 2,6DEP. The percentage of productivity suppressed by amine titration was calculated to be $88 \%, 81 \%$, and $72 \%$, respectively, for 2,6DMP, 2,6DEP, and 2,6DTBP by Equation (4). Productivity was reported instead of rate, because the activities were not measured under differential condition (i.e., initial conversion was above $10 \mathrm{C} \%$ ). Similar to titration on methanol dehydration, residual productivities of methyl lactate consumption were likely due to the presence of sites that are accessible to the smaller methyl lactate but not to the bulkier amines. ${ }^{15}$

Despite the significant differences in cumulative amine uptake among the three amines, the percentage of productivity suppressed is comparable among all three amines. 2,6DMP is commonly used as a BAS specific titrant due to the methyl groups at the 2 and 6 position of the pyridine ring. ${ }^{14,49-51}$ Similarly, 2,6DEP, with ethyl groups adjacent to the amine $\mathrm{N}$, is expected to exhibit selective BAS adsorption. Therefore, the high cumulative amine uptake values observed with 2,6DMP and 2,6DEP are not likely caused by nonselective site binding on both Lewis acid sites and BAS. Alternatively, as the size of 2,6DTBP is comparable to the window size of zeolite Y, pore blockage by bulky amines can also suppress catalyst activity even with a low amine uptake. We believe that the similar extents of rate suppression is caused by pore blockage in addition to acid site poisoning. ${ }^{9,52}$

Activity suppression via pore blockage is also supported by the relative size of amine and titrant 
(a)

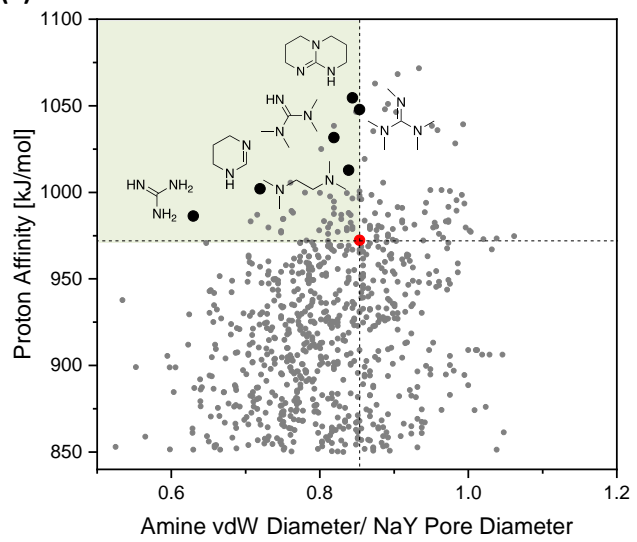

(c)

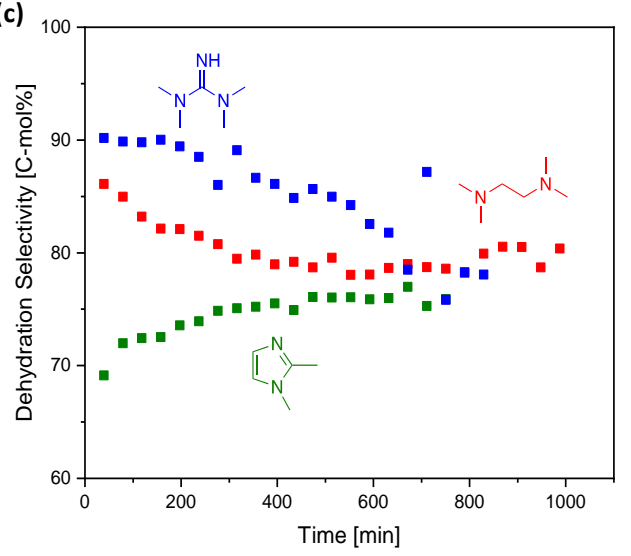

(b)

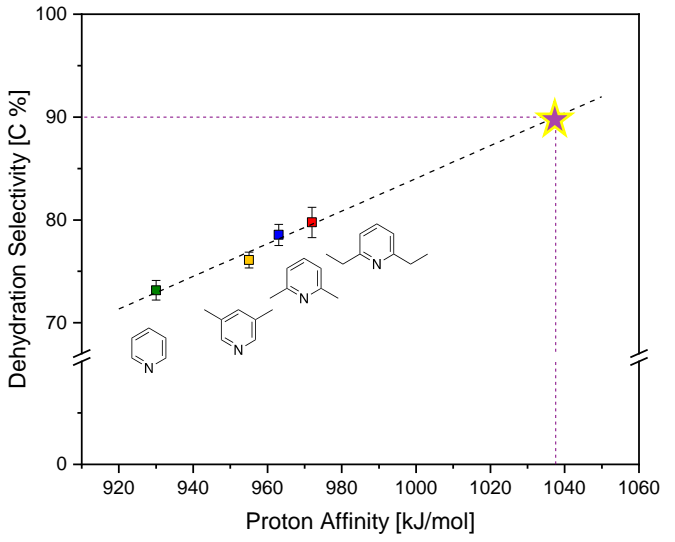

(d)

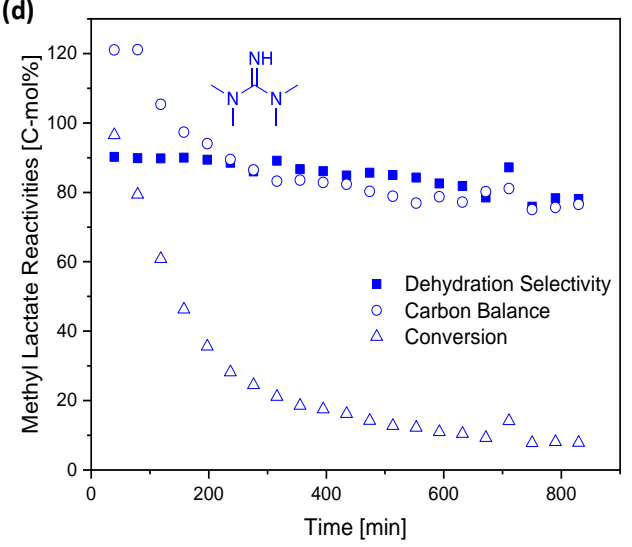

Figure 9. (a) Bases with proton affinity ${ }^{1}$ between $850 \mathrm{~kJ} / \mathrm{mol}$ and $1100 \mathrm{~kJ} / \mathrm{mol}$ was screened. 2,6DEP is denoted in a red filled circle. A green region is defined with proton affinity higher than that of 2,6DEP and size smaller than that of 2,6DEP. Bases within the green region should exhibit high basicity and low sterics favoring further enhancement in methyl lactate dehydration selectivity; (b) Potentially, a dehydration selectivity as high as $90 \%$ may be achieved with optimal bases of high basicity and low sterics in the green region in (a). Error bars in (b) are $95 \%$ confidence intervals estimated from error propagation with methods in Supplementary Note 2. The dehydration selectivities with 1,1,3,3,tetramethylguanidine (blue), N,N,N',N',-tetramethylethylenediamine (red), and 1,2-dimethylimidazole as cofeed titrant are compared in (c). The dehydration selectivity, carbon balance, and conversion with 1,1,3,3,tetramethylguanidine are shown in (d). Reaction condition: $\mathrm{NaY}, 30{ }^{\circ} \mathrm{C}, \mathrm{P}_{\text {total }}=101.3 \mathrm{kPa}\left(\mathrm{P}_{\text {methyl lactate }}=78.0 \mathrm{~Pa}, \mathrm{P}_{\text {amine }}\right.$ $=7.8 \mathrm{~Pa}, \mathrm{P}_{\text {water }}=1.1 \mathrm{kPa}$, balanced by helium at a flowrate of $90 \mathrm{~mL} \mathrm{~min}^{-1}$ ), and WHSV $=0.9 \mathrm{~h}^{-1}$.

molecules with respect to the volume of zeolite Y supercage. The space occupied by molecules can be calculated by the van der Waals volumes, and the volume of a zeolite $\mathrm{Y}$ supercage has been estimated to be $667 \AA^{3}$ by the method in section 4.4.2. The number of amines that can be packed within the supercage decreases in the order of 2,6DMP, $2,6 \mathrm{DEP}$, and 2,6DTBP in the presence methanol or methyl lactate (Figure 8c and d). The remaining space in the void can be occupied by the smaller methanol or methyl lactate, resulting in residual activity at adsorption saturation. At a $\mathrm{Si} / \mathrm{Al}$ ratio of 2.55, theoretically, there can be seven Al sites per supercage on average, ${ }^{53-55}$ and the presence of adjacent sites is possible. The adsorption of bulky amine including 2,6DTBP on one BAS can physically block multiple adjacent BAS, while smaller amines are more likely to chemically titrate more BAS in a confined environment due to their smaller overall sizes. It is therefore unsurprising that the cumulative amine uptakes vary by a factor of $\sim 5 x$, yet 2,6DTBP still exhibited a similar extent of reactivity suppression to those of 2,6DMP and 2,6DEP. Notably, catalyst deactivation was observed prior to amine titration, but correcting the titration curves for catalyst deactivation does not change the results for the cumulative amine uptakes 
or the percentages of productivity suppression (Supplementary Note 11).

Overall, the lower binding strength calculated from DFT calculations as well as low site accessibility observed experimentally shows that BAS adsorption by 2,6DTBP is hindered by the local steric limitations of the amine. Even given sufficient time to overcome internal diffusion limitations, amines with high degree of local steric limitations such as 2,6DTBP would still not be able to exhibit desirable BAS titration to promote selective lactic acid dehydration to acrylic acid. For further selectivity enhancement, a search is necessary for titrants with high basicity and small size.

2.6 Prediction on the Optimal Amines/Bases. While we utilize amine basicity for BAS titration to eliminate side reactions, amine steric limitations remain the limiting factor that prevents the achievement of selectivity above $90 \mathrm{C} \%$ in methyl lactate dehydration. Therefore, amines with high basicity but low steric constraints are desirable for methyl lactate dehydration within porous solid acid catalysts. To facilitate the search, $\sim 800$ bases with various proton affinities $^{34}$ and sizes were considered. As shown in Figure 9a, a region with bases with proton affinity higher and size smaller than those of 2,6DEP is highlighted in green. The 46 bases in the green region, listed in Table S5, should exhibit strong BAS binding due to the high basicity and low steric constraints. When the effect of amine steric limitations is minimal, amine basicity will determine BAS titration and further improve dehydration selectivity with the increase in basicity. Potentially, optimal bases with proton affinity above $1037 \mathrm{~kJ} / \mathrm{mol}$ from the green region may yield greater than $90 \mathrm{C} \%$ methyl lactate dehydration selectivity, passed on linear extrapolation from unhindered aromatic amines (Figure 9b).

Selected bases within the green region were examined for methyl lactate dehydration selectivity enhancement. Under co-feed conditions at $300{ }^{\circ} \mathrm{C}$, dehydration selectivity above $80 \mathrm{C} \%$ can be experimentally achieved with amines from the green region of Figure 10a. In particular, a dehydration selectivity of $89 \mathrm{C} \%$ was observed with 1,1,3,3-tetramethylguanidine (TMG) for the first five hours of co-feed experiment (Figure 9c) but decreases with time to $80 \mathrm{C} \%$ at $10 \mathrm{~h}$ TOS. As the proton affinity of TMG is $1032 \mathrm{~kJ} / \mathrm{mol}$ (Table
S5), which is close to the basicity value predicted in Figure $9 \mathrm{~b}$ for $90 \mathrm{C} \%$ dehydration selectivity, the 89 C-mol\% dehydration selectivity achieved with TMG is not surprising. However, the unsteady dehydration selectivity over time accompanied by a decrease in carbon balance to below $80 \mathrm{C} \%$ beyond five hours time-on-stream (Figure 9d) indicates that TMG, albeit a strong base, is unstable under reaction conditions and is not desirable for industrial applications.

The dilemma is that high basicity often corresponds to high reactivity, because the highly basic functional group can act as a strong nucleophile. TMG, a strong base, may have reacted with acrylic acid in the reaction system, resulting in loss of carbon and lower dehydration selectivity. Therefore, in addition to high basicity and small size, molecule stability should be another factor for the design of desirable titrant to achieve above 90 $\mathrm{C} \%$ selectivity in industrial applications. Further examination on amines within the green region is required to identify stable and highly basic titrant for methyl lactate dehydration selectivity enhancement; this is the focus of future work.

3.0 Conclusions. In this work, we have demonstrated the use of stronger co-fed Bronsted acid site (BAS) titrants for selectivity control via suppression of side reactions. Amines with different basicity and size improve methyl lactate dehydration selectivity from $61 \mathrm{C} \%$ up to $84 \mathrm{C} \%$ over NaY. Surprisingly, dehydration selectivity does not increase monotonically with basicity but achieves a maximum using 2,6-diethrylpyridine $(2,6 \mathrm{DEP})$ titrant with moderate basicity of 972 $\mathrm{kJ} / \mathrm{mol}$ and a size around $85 \%$ of the $\mathrm{NaY}$ pore diameter. The effectiveness of BAS titration is found to be controlled by both the titrant basicity and steric limitations. As the size of titrant molecule increases, steric hindrances start to outweigh the effect of amine basicity and limit BAS accessibility in the form of internal diffusion limitations and local steric constraints. Bulky amines such as 2,6diisopropylpyridine (2,6DIPP) and 2,6ditertbutylpyridine (2,6DTBP) were shown to diffuse slower by one or two orders of magnitude than smaller amines such as pyridine through MD simulations. Pre-saturating the $\mathrm{NaY}$ catalyst bed with bulky amines significantly enhanced methyl lactate dehydration selectivity, indicating that internal diffusion hinders BAS accessibility by 
bulky amines such as 2,6DIPP and 2,6DTBP. Another form of steric limitation arises from the interactions between amine and the zeolite framework surrounding a BAS. Density Functional Theory (DFT) was used to calculate adsorption, stabilization, and distortion energies between amine and a BAS in zeolite $\mathrm{Y}$ to reveal that BAS binding by bulky amines such as 2,6DTBP is hindered due to the local steric interactions; this is further also supported by the limited site accessibility to 2,6DTBP measured by in situ amine titration on methyl lactate decarbonylation over HY. Therefore, the optimal amine or base that yields better selectivity enhancement than the existing selectivity maximum should have a proton affinity above $972 \mathrm{~kJ} / \mathrm{mol}$ and size below $85 \%$ of the NaY pore size. Selected bases that satisfy the criterion afforded dehydration selectivity as high as $89 \mathrm{C} \%$ but showed selectivity decrease over long TOS due to low stability. We propose that the results of this study can be utilized to further improve methyl lactate dehydration selectivity beyond $90 \mathrm{C} \%$ using stable titrants that achieve sufficient metrics for basicity and size.

\subsection{Materials and Methods.}

4.1 Materials Preparation. Prior to materials characterization and reactivity measurements, $\mathrm{NaY}$ (Zeolyst International, CBV-100, Si/Al = 2.6, lot\# 100031080671 ) and $\mathrm{NH}_{4}{ }^{+}-\mathrm{Y}$ (Zeolyst International, CBV-500, Si/Al = 2.6, lot \# 400054002618) zeolite catalysts were calcined at $550{ }^{\circ} \mathrm{C}$ for 12 hours with a $1.0^{\circ} \mathrm{C} / \mathrm{min}$ ramp rate to remove water and residual organic compounds. CBV-500 was originally in the ammonium form and was converted into proton form (HY) after calcination. All chemicals, namely HPLC grade water, methyl lactate [98\%], acetaldehyde [99.5\%], methanol [99.9\%], methyl acrylate [99\%], 2,3-pentanedione [97\%], methyl pyruvate [95\%], acrylic acid [99\%], pyridine [99.8\%], 3,5- dimethylpyridine [98\%], 2,6dimehylpyridine [99\%], 2,6-diethylpyridine [95\%], 2,6-diisopropylpyridine [97\%], 2,6ditertbutylpyridine [97\%], 1,2-dimethylimidazole [98\%], N,N,N',N',-tetramethylethylenediamine [99.5\%], and 1,1,3,3-tetramethylguanidine [99\%] were purchased from Sigma Aldrich and used as received.
4.2 Materials Characterization. Textural information of the $\mathrm{NaY}$ and $\mathrm{HY}$ zeolite samples was obtained using argon physisorption at $87 \mathrm{~K}$. Isotherms were collected by an Autosorb iQ2 porosimetry instrument from Quantachrome. Pore volume and pore size distribution were calculated using the Saito-Foley method with cylindrical pore geometry. Prior to physisorption measurements, the samples were outgassed to remove absorbed water at $300{ }^{\circ} \mathrm{C}$ for six hours and cooled to room temperature under vacuum in the degas port of the instrument. Powder X-ray diffraction (XRD) patterns were collected with a Bruker AXS D5005 diffractometer using $\mathrm{Cu} K_{\alpha}(\lambda=1.5418 \AA)$ as the radiation source to verify the framework type and crystallinity of $\mathrm{NaY}$ and HY. Inductively Coupled Plasma Optical Emission Spectrometry (ICP-OES) was used to confirm the $\mathrm{Si} / \mathrm{Al}$ ratio of the zeolite samples. Solid state ${ }^{27}$ Al-MAS NMR on a Bruker DSX-500 with a Bruker $4.0 \mathrm{~mm}$ MAS probe was used to detect the existence of extra-framework aluminum in the $\mathrm{NaY}$ and $\mathrm{HY}$ sample. The chemical shifts were calibrated with $\mathrm{AlCl}_{3}$ as the standard reference for octahedral $\mathrm{Al}^{56}$

The concentration of BAS on the freshly calcined NaY sample was quantified using the reactive gas chromatography (RGC) method previously developed by Dauenhauer and coworkers. ${ }^{8}$ Prior to RGC analysis, the NaY zeolite sample (calcined ex-situ at $550{ }^{\circ} \mathrm{C}$ by the method of section 2.1) was calcined at $400{ }^{\circ} \mathrm{C}$ for one hour with a ramp rate of $10{ }^{\circ} \mathrm{C} \mathrm{min}^{-1}$ to further remove water absorbed during sample storage. At $150{ }^{\circ} \mathrm{C}$, tert-butylamine was dosed by pulse injections from the automatic liquid sampler on the freshly calcined $\mathrm{NaY}$ sample until saturation. The excess and physiosorbed tert-butylamine was purged by helium for two hours; the remaining tertbutylamine were chemisorbed on Brønsted acid sites of the catalyst sample. Then the NaY sample was subjected to a linear temperature increase at a ramp rate of $10^{\circ} \mathrm{C} \mathrm{min}-1$ to $250^{\circ} \mathrm{C}$, during which the chemisorbed tert-butylamine underwent Hofmann elimination to produce isobutene and ammonia. Isobutene was accumulated in the GC column at 30 ${ }^{\circ} \mathrm{C}$ and was released to FID for quantification as the column temperature ramped linearly to $270{ }^{\circ} \mathrm{C}$ with a rate of $10^{\circ} \mathrm{C} \mathrm{min}^{-1}$. The area of the isobutene peak from the FID was calibrated with ZSM-5 ( Si/Al = 140, CBV-28014) of known BAS concentration to 
estimate the amount of Brønsted acid sites in the $\mathrm{NaY}$ sample. The BAS density of $\mathrm{NaY}$ and HY were also measured with in situ titration experiments, which will be discussed in detail in section 4.3.3.

4.3 Reaction Activity Measurements. All reactivity measurements were performed at atmospheric pressure using a micro-flow catalytic packed bed reactor contained in a modified gas chromatography (GC) inlet as described in our previous work $^{57}$. A detailed reactor design is shown in Figure S1 and Supplementary Note 2. The temperature and gas flowrate were precisely controlled by the Agilent 7890B GC. The catalyst bed was comprised of $20 \mathrm{mg}$ of ex-situ calcined (with method described in section 2.1) zeolite sample sandwiched between two layers of deactivated quartz wool (Restek, CAS. \#20789). Prior to the reaction, the catalyst bed was calcined in situ with air at $400{ }^{\circ} \mathrm{C}$ for five hours with a ramp rate of $3{ }^{\circ} \mathrm{C} \mathrm{min}^{-1}$. A continuous liquid reactant flow was fed by a Cole-Parmer 78-8110C syringe pump to a vaporizer embedded in the valve box of the GC, where the liquid reactant feed was vaporized and carried by the carrier gas helium to other gas lines in the reactor. Similarly, titrant amines were introduced to the reactor system using a separate Cole-Parmer 78-8110C syringe pump. The feed streams containing reactant and titrant were directed using the switching valve in GC to flow through or bypass the catalyst bed (Figure S2).

The reactor effluent was separated by an HPFFAP column (Agilent Technologies) with a ramp rate of $10{ }^{\circ} \mathrm{C} \mathrm{min}^{-1}$ from $50{ }^{\circ} \mathrm{C}$ to $240{ }^{\circ} \mathrm{C}$ and analyzed a quantitative carbon detector (QCD, Polyarc $\left.{ }^{\mathrm{TM}}\right)^{58}$ in conjunction with a flame ionization detector (FID). Due to the QCD, the molar flowrate of carbons associated with each species can be directly measured using one pre-determined calibration factor.

4.3.1 Amine Co-feed Experiments. Methyl lactate dehydration was evaluated over $\mathrm{NaY}$ with co-fed amines at $300{ }^{\circ} \mathrm{C}$. NaY was loaded to the catalyst bed and $30 \mathrm{wt} \%$ methyl lactate aqueous solution was fed to the reactor at a flowrate of 1.0 $\mu L \min ^{-1}$. Amine was introduced in a separate feed stream to the reactor with a flowrate to attain a 10:1 ratio of methyl lactate: amine. ${ }^{17,18}$ At the beginning of each experiment, four bypass runs were performed and averaged to measure the total molar flowrate of carbons from methyl lactate, $\dot{N}_{M L 0}$, entering the reactor system. The carbon balance was defined by Equation (5),

carbon balance $=$

$\frac{\dot{N}_{C O}+\dot{N}_{A C}+\dot{N}_{M T}+\dot{N}_{M A}+\dot{N}_{P D}+\dot{N}_{M P}+\dot{N}_{M L}+\dot{N}_{A A}}{\dot{N}_{M L 0}} \times 100 \%$

where $A C$ is acetaldehyde, $M T$ is methanol, $M A$ is methyl acrylate, $P D$ and $M P$ are minor side products, 2,3-pentanedione and methyl pyruvate, respectively, $M L$ is methyl lactate, and $A A$ is acrylic acid. All the molar flowrates are carbon molar flowrates of the corresponding species in the unit of moles of carbon per minute. The carbon-based conversion and molar reaction rate were calculated as,

$$
\begin{gathered}
\text { conversion }= \\
\frac{\dot{N}_{C O}+\dot{N}_{A C}+\dot{N}_{M T}+\dot{N}_{M A}+\dot{N}_{P D}+\dot{N}_{M P}+\dot{N}_{A A}}{\dot{N}_{M L 0}} \times 100 \% \\
\text { rate }_{i}=\frac{\dot{N}_{i}}{\text { mumber of carbons in } i}
\end{gathered}
$$

where $i$ represents species $i$ in the system. Carbon balances for all experiments are shown in Figure S2. Productivity was reported instead of rate using the same Equation (7) when the reactions were not operated under differential condition. The dehydration pathway selectivity (or dehydration selectivity) was calculated as,

\section{dehydration selectivity $=$}

$\frac{\dot{N}_{M A}+\dot{N}_{A A}+\dot{N}_{M T_{-} D H}}{\dot{N}_{C O}+\dot{N}_{A C}+\dot{N}_{M T}+\dot{N}_{M A}+\dot{N}_{P D}+\dot{N}_{M P}+\dot{N}_{A A}} \times 100 \%$

$\dot{N}_{M T_{-} D H}$ is the molar flowrate of carbons of methanol from the dehydration pathway and is assumed to be $\frac{1}{3} \dot{N}_{A A}$. The carbon balance on methanol shows that methanol was conserved in the form of methyl acrylate, methyl lactate, methyl pyruvate, and methanol itself (Figure S2). The unit of carbon balance, conversion, and dehydration selectivity is $\mathrm{C} \%$ or mol\%. The weight hourly space velocity (WHSV) was defined as, 


$$
W H S V=\frac{\text { mass flowrate of reactant }}{\text { mass of catalyst }}
$$

The stability of amines at $300{ }^{\circ} \mathrm{C}$ was examined by flowing selected amines used in this study, namely pyridine, 2,6-diethylpyridine, and 2,6ditertbutylpyridine, at the same partial pressure as that in the co-feed experiment over $\mathrm{NaY}$ and $\mathrm{HY}$. No reactivities were observed with the three amines.

4.3.2 Amine Pre-saturation Experiments. For the experiments presented in Figure 5 addressing the internal diffusion limitations of cofeed amines, NaY catalyst bed was pre-saturated with amine by flowing amine through the catalyst bed for 24 hours with the same flowrate as in the co-feed experiments. After pre-saturation, methyl lactate was co-fed with amine over $\mathrm{NaY}$ at the molar ratio of 10:1 of methyl lactate: amine at the same flowrates as in the co-feed experiments. The resulting reactivities were measured and calculated in the same manner as in section 2.3.1.

4.3.3 In situ Titration Experiments. BAS density of $\mathrm{HY}$ and $\mathrm{NaY}$ was also determined by in situ titration of methanol dehydration using 2,6dimethylpyridine as titrant due to its higher BAS selectivity compared with pyridine. ${ }^{14,15}$ The in situ titration measurements were performed on the reactor setup described in section 2.3.1 and Supplementary Note 2. While 2,6-dimethylpyridine desorbs at $240{ }^{\circ} \mathrm{C}$ from sodium acidic sites on $\mathrm{NaY},{ }^{59}$ the desorption temperature from BAS on $\mathrm{HY}$ is expected to be higher than $240{ }^{\circ} \mathrm{C}$ due to formation of hydrogen bonding. ${ }^{60,61}$ The desorption temperature is also expected to be higher than 240 ${ }^{\circ} \mathrm{C}$ for amines with higher basicity than 2,6dimethylpyridine, as observed with the increase in desorption temperature from $150{ }^{\circ} \mathrm{C}$ with the weaker base pyridine to above $240{ }^{\circ} \mathrm{C}$ with the stronger base 2,6-dimethylpyridine from $\mathrm{BAS}^{62}$ Therefore, a reaction temperature below $240{ }^{\circ} \mathrm{C}$ ensures irreversible adsorption on BAS for amines with the same or higher basicity than 2,6dimethylprydine.

For the HY catalyst sample with the same $\mathrm{Si} / \mathrm{Al}$ ratio as that of $\mathrm{NaY}$ used in co-feed experiments, methanol was delivered at $150{ }^{\circ} \mathrm{C}$ at a partial pressure of $1 \mathrm{kPa}$ to achieve differential conversion at $\sim 3 \%$. Dimethyl ether was the only observed product from methanol on $\mathrm{HY}$ at the specified reaction temperature. At steady conversion and dimethyl ether synthesis rate, $2 \mathrm{~Pa}$ of 2,6dimethylpyridine, 2,6-diethylpyridine, or 2,6ditertbutylpyridine was introduced to quench methanol dehydration. When amine adsorption reached saturation, the rate of dimethyl ether formation only fluctuated within $0.1 \%$ for one hour, and the cumulative amine uptake at saturation yielded an estimate for the BAS density of $\mathrm{HY}$ as well as BAS accessibility to the selected amines. Methanol was also fed to $20 \mathrm{mg}$ of $\mathrm{NaY}$ at a partial pressure of $1 \mathrm{kPa}$. The conversion of methanol on $\mathrm{NaY}$ was evaluated at $150,180,230$, and $300{ }^{\circ} \mathrm{C}$ prior to the introduction of 2,6-dimethylpyridine to measure BAS count. However, no methanol reactivity was observed over $\mathrm{NaY}$ even at $300{ }^{\circ} \mathrm{C}$ due to the lower activity of sodium sites on $\mathrm{NaY}$, indicating the lack of Brønsted acidity in this material.

The BAS accessibility by amine under competition with methyl lactate was measured with in situ titration experiments using methyl lactate decarbonylation as the probe reaction. HY was used to directly estimate the competition between methyl lactate displacement and amine adsorption on Brønsted acid sites. The reaction temperature of $180{ }^{\circ} \mathrm{C}$ was selected to achieve irreversible amine adsorption $^{59}$ and measurable methyl lactate decarbonylation activities. The partial pressure of methyl lactate and water as well as the weight hourly space velocity (WHSV) remained the same as in the amine co-feed experiments. Methyl lactate flowed through the $\mathrm{HY}$ catalyst bed at $180{ }^{\circ} \mathrm{C}$ until conversion fluctuated only $\sim 1 \%$ within one hour. A steady stream of amine was then introduced at a molar ratio of methyl lactate: amine of 240:1 to maintain the same partial pressure of methyl lactate before and after amine introduction and to ensure appropriate timescales for rate quenching measurements based on the temporal resolution of GC methods. The reaction was allowed to proceed until a new steady state conversion was reached with fluctuation within $0.1 \%$ for one hour.

4.4 Computational Methods. In addition to reactivity measurements by experiments, the adsorption of amines in zeolite $\mathrm{Y}$ were also evaluated with computation. The proton affinity of methoxy oxygen of methyl lactate was calculated by density functional theory (DFT) and the size of amine molecules was estimated by calculated 
molecular size descriptors. The size of zeolite $\mathrm{Y}$ supercage was estimated from the occupiable volume of zeolite Y. Internal diffusion was evaluated by calculating the self-diffusion coefficient of amines in zeolite $\mathrm{Y}$ using molecular dynamics (MD). Additionally, the local steric interactions between amine and zeolite framework around a BAS and amine adsorbed on a BAS were computed using density DFT calculations to quantify the local steric interactions.

4.4.1 Proton Affinity Calculations. Proton affinity (PAFF) is defined as the negative of molar enthalpy change at $298.15 \mathrm{~K}$ for the reaction listed in Equation (11).

$$
A+H^{+} \rightarrow A H^{+}
$$

Assuming ideal gas behavior, the protonation reaction enthalpy $\left(\Delta H_{r x n}\right)$ can be obtained from the change in internal energy $\left(\Delta E_{r x n}\right)$ as:

$$
\Delta H_{r x n}=\Delta E_{r x n}-\mathrm{RT}=-\mathrm{PAFF}
$$

where $\mathrm{R}$ is the gas constant and $\mathrm{T}$ is temperature. The internal energy $E(T)$ of a nonlinear polyatomic molecule can be approximated as the summation of translational $\left(E_{\text {trans }}\right)$, rotational $\left(E_{\text {rot }}\right)$, vibrational $\left(E_{v i b}\right)$, and electronic energies $\left(E_{\text {elec }}\right){ }^{63}$

$$
E(T)=E_{\text {trans }}+E_{\text {rot }}+E_{\text {vib }}+E_{\text {elec }}
$$

The contributions from $E_{\text {trans }}$ and $E_{\text {rot }}$ are both $\frac{3}{2} R T . E_{v i b}$ can be decomposed as the summation of the zero point energy (ZPE) and a temperature dependent portion $E^{\prime v i b}(T)$, which is generally negligible compared with ZPE. As the proton only possess translational energy of $\frac{3}{2} R T$, proton affinity can be obtained from the change in electronic energies and zero point energies due to protonation with the following equation:

$$
P A F F=-\Delta E_{\text {ele }}-\triangle Z P E+\frac{5}{2} R T
$$

The gas-phase ground-state electronic energies and zero point energies of the molecules before and after protonation were calculated by DFT using Gaussian $16^{64}$ with the B3LYP functional and 6$311++\mathrm{G}(3 \mathrm{df}, 3 \mathrm{pd})$ basis set $^{65,66}$. The calculated proton affinity values are in agreement with reported values from experiment measurements ${ }^{34}$ (Figure S6), showing the validity of estimating gasphase proton affinities using the described method. The proton affinity of the methoxy oxygen of methyl lactate was then calculated with the same method.

4.4.2 Molecular Size Descriptor and Supercage Volume Calculations. The size of molecules can be quantified by spatial descriptors that differ in describing the boundary of an electronic molecular orbital. Here, we first calculated several size descriptors and selected one to define the size of amine or base molecules in this study. The four descriptors compared include:

- The 'effective diameter' defines the diameter of the smallest cylinder into which the molecule can fit.

- The 'maximum diameter' is the diameter of a fully relaxed molecule modeled in the shape of a sphere.

- The 'van der Waals volume' of a molecule is the sum of volumetric contribution of individual atoms modeled as sphere based on bond distances, bond angles, and intermolecular van der Waals radii. ${ }^{67}$

- The 'kinetic diameter' indicates the probability of molecular collisions in gas phase.

The effective diameter, maximum diameter, and van der Waals volume were calculated using the QSAR Toolbox (version 4.3.1). The van der Waals diameter was calculated from the van der Waals volume, assuming the molecules are spherical, by Equation (15),

$$
d_{v d W}=2 \times\left(\frac{3 V_{v d W}}{4 \pi}\right)^{\frac{1}{3}}
$$

where $d_{v d W}$ is the van der Waals diameter and $V_{v d W}$ is the calculated van der Waals volume. The kinetic diameter $\left(d_{k}\right)$ can be calculated from the critical volume $\left(V_{c}\right)$ or critical temperature $\left(T_{c}\right)$ and pressure $\left(P_{c}\right)$ of a fluid, ${ }^{68}$

$$
\begin{aligned}
& d_{k}=0.841 V_{c}^{1 / 3} \\
& d_{k}=2.44\left(\frac{T_{c}}{P_{c}}\right)^{1 / 3}
\end{aligned}
$$

where $V_{c}$ is in $\mathrm{cm}^{3} \mathrm{~mol}^{-1}, T_{c}$ is in $\mathrm{K}$, and $P_{c}$ is in atm. However, data for the critical properties are not readily available for all amines in this study. 
Alternatively, the kinetic diameter can also be estimated from the molecular weight (MW) of the molecule for aromatic hydrocarbons: ${ }^{69}$

$$
d_{k}=1.234(M W)^{1 / 3}
$$

The volume of zeolite $\mathrm{Y}$ supercage is calculated from the occupiable volume of zeolite $\mathrm{Y}$ $\left(V_{o c c}\right), 370 \AA^{3}$, defined as the open volume that can be occupied by $2.8 \AA^{3}$ spheres in the zeolite Y framework within a $1000 \AA^{3}$ cube $^{70}$ using Equation (19).

$$
\text { Supercage Volume }=\frac{1}{N} V_{\text {unit cell }} \frac{V_{\text {occ }}}{1000 \AA^{3}}
$$

$\mathrm{N}$ is the number of supercages per unit cell, which is eight in a unit cell with volume $\left(V_{\text {unit cell }}\right)$ of $24.345 \times 24.345 \times 24.345 \AA^{3} .{ }^{71-73}$

4.4.3 Molecular Dynamics (MD) Simulations of Amine Diffusion in Zeolite Y. Molecular diffusion in confined pores can be hindered by structural interactions within a confining environment. ${ }^{74} \mathrm{MD}$ simulations were performed with using the Large-scale Atomic and Molecular Massively Parallel Software (LAMMPS) version 5 June 2019 to compute amine diffusion in zeolite $\mathrm{Y}$ using the MedeA Environment by Materials Design $^{\circledR}$. An all-silica zeolite $\mathrm{Y}$ unit cell $(24.345 \times$ $24.345 \times 24.345 \AA^{3}, \alpha, \beta, \gamma=90^{\circ}$ ) with 3 -D pore channels was obtained from the International Zeolite Association (IZA) database, and all sodium cations were removed from the zeolite $\mathrm{Y}$ unit cell. A $2 \times 2 \times 2$ supercell $(48.690 \times 48.690 \times 48.690$ $\AA^{3}, \alpha, \beta, \gamma=90^{\circ}$ ) was generated from the sodiumfree zeolite $\mathrm{Y}$ unit cell. The all-atom PCFF+ forcefield, modified by Materials Design from the PCFF forcefield, ${ }^{75}$ was selected to model molecular diffusion in zeolite Y. Periodic boundary conditions were applied in all three dimensions. A potential cutoff of $9 \AA$ was employed for short-ranged interactions, and the particle-particle-particle mesh (PPPM) Ewald sum was applied to simulate longranged Coulombic interactions. An equilibration simulation was performed on the empty supercell to test the stability of the supercell with the PCFF+ forcefield. The supercell was first equilibrated with a 1.0 fs time step at constant $300{ }^{\circ} \mathrm{C}$ and $1.0 \mathrm{~atm}$ (NPT) with a Nosé-Hoover (NH) barostat and thermostat for $100 \mathrm{ps}$. The resulting structure was further equilibrated in the isochoric isothermal ensemble (NVT) for $100 \mathrm{ps}$ with temperature fixed by the $\mathrm{NH}$ thermostat. The temperature, pressure, and energy profiles are shown in Supplementary Note 7 . The resulting equilibrated framework was then used in the diffusion simulations.

To further validate the choice of zeolite framework and forcefield, sample calculations on water diffusion in zeolite $\mathrm{Y}$ were performed at 300 ${ }^{\circ} \mathrm{C}$ and $1.0 \mathrm{~atm}$ to compare with a literature study using LAMMPS. ${ }^{76}$ A total of 411 water molecules were randomly distributed in the equilibrated zeolite Y framework. The framework was frozen, and water molecules were allowed to move freely in the framework. A $200 \mathrm{ps}$ isochoric isothermal (NVT) simulation with $1.0 \mathrm{fs}$ time step was used to relax the system and the $\mathrm{NH}$ thermostat was employed. The diffusion properties of water were determined over a $5.0 \mathrm{~ns}$ simulation with a $1.0 \mathrm{fs}$ time step. The self-diffusion coefficient $\left(D_{S}\right)$ of water can be calculated from the mean-square displacement (MSD), which should be linearly dependent on time according to the Einstein Relation,

$$
M S D(t)=\frac{1}{N} \lim _{t \rightarrow \infty}\left\langle\sum_{i=1}^{N}\left|r_{i}(t)-r_{i}(0)\right|^{2}\right\rangle=6 D_{s} t
$$

Four independent trials with different initial water molecule distributions were conducted to minimize the effect of initial configurations. The resulting self-diffusion coefficients were comparable to literature values from both computation and experiment, validating the choice of framework and force field (details in Supplementary Note 7).

Diffusion simulations of amines in zeolite $\mathrm{Y}$ were performed at $300{ }^{\circ} \mathrm{C}$ and $1.0 \mathrm{~atm}$ using the same procedure. A total of 10 amines were randomly placed in a $2 \times 2 \times 2$ equilibrated supercell to approximate amine uptake in zeolite $\mathrm{Y}$ (details in Supplementary Note 7). Diffusion properties were calculated with the same steps and methods as in the water diffusion simulation. The self-diffusion coefficient of each amine in the zeolite Y framework was evaluated with 20 independent trials with different initial amine distributions in the zeolite supercell.

4.4.4 Density Functional Theory (DFT) Calculations of Amine Adsorption on zeolite Y. All calculations of amine adsorption on a BAS 
within the zeolite $\mathrm{Y}$ framework were performed using periodic DFT with the Vienna Ab Initio Simulation Package (VASP) ${ }^{77}$ version 5.4.4 incorporated in the MedeA Environment. The generalized gradient corrected Perdew-BurkeErnzerhof $(\mathrm{GGA}-\mathrm{PBE})^{78}$ exchange correlation functional was employed in all calculations with a plan-wave basis set and the projector augmented wave (PAW) potentials, where $\mathrm{Si}(3 \mathrm{~s} 3 \mathrm{p}), \mathrm{O}(2 \mathrm{~s} 2 \mathrm{p})$, $\mathrm{Al}(3 \mathrm{~s} 3 \mathrm{p}), \mathrm{H}(1 \mathrm{~s}), \mathrm{C}(2 \mathrm{~s} 2 \mathrm{p})$, and $\mathrm{N}(2 \mathrm{~s} 2 \mathrm{p})$ were included explicitly in the valence. ${ }^{79,80}$ A cutoff of the plane-wave basis of $450 \mathrm{eV}$ along with the $\Gamma$ point sampling of reciprocal space was used. DFTD3 with Becke-Johnson (BJ) - damping was used to include dispersion interactions between the adsorbate and zeolite. ${ }^{81,82}$ A Gaussian smearing of $0.05 \mathrm{eV}$ was applied at the Fermi level, and the total energies were extrapolated to zero smearing. Geometry optimizations were converged to an energy threshold of $10^{-5} \mathrm{eV}$ and a force threshold of $0.02 \mathrm{eV}^{-1}$.

The initial structure for the all silicate zeolite $\mathrm{Y}$ periodic unit cell $\left(24.345 \times 24.345 \times 24.345 \AA^{3}\right.$, $\alpha, \beta, \gamma=90^{\circ}$ ) was again obtained from the International Zeolite Association (IZA) database and all sodium cations were removed from the framework prior to optimization. One silicon atom on the 12-member ring window of a supercage was replaced by an aluminum atom. The resulting negative charge on an adjacent oxygen to the aluminum was balanced by a proton, which resulted in the addition of a BAS to the zeolite Y framework (Figure S16a). All atomic positions and lattice constants were relaxed for the empty framework. Amine molecules were optimized individually in a fixed unit cell $(25.000 \times 25.000 \times 25.000 \AA$, $\alpha, \beta, \gamma=90^{\circ}$ ) prior to adsorption simulations. The energy-minimized amine was then placed near the introduced BAS with the amine nitrogen facing the Brønsted proton. The initial $\mathrm{N}-\mathrm{H}$ distances for all amines were close to one bond length of the $\mathrm{N}-\mathrm{H}$ bond in the pyridinium cation. ${ }^{47}$ Structural optimization was employed on the zeolite-amine system assuming a rigid framework approximation (i.e., only the positions of the amine are relaxed in the optimization) with the exception of the BAS proton, oxygen, aluminum, and silicon, which were allowed to move during the optimization.

The total electronic energies of the optimized structures for zeolite $\left(E_{Z}\right)$, amine $\left(E_{A}\right)$, and the zeolite-amine system $\left(E_{A Z}\right)$ were used to calculate adsorption energies of the amine on zeolite $\mathrm{Y}$ as shown in Equation (1). The structure of the amine in the zeolite-amine adsorbed optimized geometry was extracted, deprotonated, and frozen. A structure optimization calculation was performed for the isolated adsorbed amine $\left(E_{A_{-} a d s}\right)$. The energy difference, defined as distortion energy, between amine in the adsorbed state $\left(E_{A_{-} a d s}\right)$ and relaxed state $\left(E_{A}\right)$ can be calculated by Equation (3) to account for the possible energy gain due to local steric interactions as adsorbate molecule bind onto the BAS. The root mean squared deviation between structure of the adsorbed and relaxed amine was also calculated using the Visual Molecular Dynamics $(\mathrm{VMD})^{83}$ to directly quantify the structural change due to local steric limitations.

The same calculations were repeated with a higher energy cutoff of $550 \mathrm{eV}$ with pyridine, 2,6diethylpyridine, and 2,6-ditertbutylpyridine. Adsorption energies for the selected amines only differed by $2 \mathrm{~kJ} / \mathrm{mol}$ compared with the values calculated at the energy cutoff of $450 \mathrm{eV}$ (Table S4), supporting the initial choice for the energy cutoff of $450 \mathrm{eV}$. In addition, the same amine adsorption calculations were performed with all atoms relaxed with 2,6-diethylpyridineand 2,6ditertbutylpyridine. Adsorption energies only changed by 10 and $7 \mathrm{~kJ} / \mathrm{mol}$ respectively (Table S4), validating the rigid framework approximation for the adsorption calculations.

Acknowledgements. We acknowledge financial support of the NSF Center for Sustainable Polymers, an NSF Center for Chemical Innovation at the University of Minnesota (CHE-1901635). We also acknowledge the farm families of Minnesota and their corn check-off investment through the Minnesota Corn Research and Promotion Council. The authors acknowledge the Minnesota Supercomputing Institute (MSI) at the University of Minnesota for providing resources that contributed to the research results reported within this paper. URL: http://www.msi.umn.edu/. The authors thank Prof. Omar Abdelrahman for valuable discussions, technical assistance, and guidance. The authors also thank Mr. Xinyu Li from University of Minnesota for providing the Xray diffractograms for all zeolite samples and the argon physisorption isotherm for the HY sample. 
Keywords. Lactic acid, faujasite, acrylic acid, dehydration, decarbonylation, amine

Supporting Information. The Supporting Information is available free of charge.

Generation of in-situ Brønsted acid sites in NaY; reactor design; materials characterization; proton affinity calculations; size descriptor selection; conversion over time and deactivation fit; molecular dynamics simulations on diffusion in zeolite $Y$; pre-saturation experiments; amine adsorption calculations by density functional theory; in-situ titration experiments; model for titrating a deactivating catalyst bed; prediction on the optimal bases

The supporting information references additional publications. ${ }^{17-19,34,57,76,84-87}$

\section{References}

(1) Lee, J. H.; Kattel, S.; Jiang, Z.; Xie, Z.; Yao, S.; Tackett, B. M.; Xu, W.; Marinkovic, N. S.; Chen, J. G. Tuning the Activity and Selectivity of Electroreduction of $\mathrm{CO} 2$ to Synthesis Gas Using Bimetallic Catalysts. Nat. Commun. 2019, 10, 1-8.

(2) Li, H.; Chai, W.; Henkelman, G. Selectivity for Ethanol Partial Oxidation: The Unique Chemistry of Single-Atom Alloy Catalysts on $\mathrm{Au}, \mathrm{Ag}$, and $\mathrm{Cu}(111)$. J. Mater. Chem. A 2019, 7, 23868-23877.

(3) Kumar, G.; Liu, D.; Xu, D.; Ren, L.; Tsapatsis, M.; Dauenhauer, P. J. DehydraDecyclization of 2-Methyltetrahydrofuran to Pentadienes on Boron-Containing Zeolites. Green Chem. 2020, 22, 41474160.

(4) Ferri, P.; Li, C.; Millán, R.; Martíneztriguero, J.; Moliner, M.; Boronat, M.; Corma, A. Impact of Zeolite Framework Composition and Flexibility on MTO Selectivity: Confinement or Diffusion? Angew. Chemie - Int. Ed. 2020, 59, 1970819715.

(5) Gounder, R.; Iglesia, E. The Catalytic Diversity of Zeolites: Confinement and Solvation Effects within Voids of Molecular Dimensions. Chem. Commun. 2013, 49, 3491-3509.
(6) Vinter, K. P.; Dauenhauer, P. J. Inert Competitive Adsorption for the Inhibition of Oligomerization of Alkenes during Alcohol Dehydration. Catal. Sci. Technol. 2018, 8, 3901-3909.

(7) Kester, P. M.; Miller, J. T.; Gounder, R. Ammonia Titration Methods to Quantify Brønsted Acid Sites in Zeolites Substituted with Aluminum and Boron Heteroatoms. Ind. Eng. Chem. Res. 2018, 57, 6673-6683. Abdelrahman, O. A.; Vinter, K. P.; Ren, L.; $\mathrm{Xu}, \mathrm{D}$; Gorte, R. J.; Tsapatsis, M.;

Dauenhauer, P. J. Simple Quantification of Zeolite Acid Site Density by Reactive Gas Chromatography. Catal. Sci. Technol. 2017, 7, 3831-3841.

(9) Liu, D.; Bhan, A.; Tsapatsis, M.; Hashimi, S. Al. Catalytic Behavior of Brønsted Acid Sites in MWW and MFI Zeolites with Dual Meso- and Microporosity. ACS Catal.

2011, 1, 7-17.

(10) Farneth, W. E.; Gorte, R. J. Methods for Characterizing Zeolite Acidity. Chem. Rev. 1995, 95, 615-635.

(11) Qi, L.; Zhang, Y.; Conrad, M. A.; Russell, C. K.; Miller, J.; Bell, A. T. Ethanol Conversion to Butadiene over Isolated Zinc and Yttrium Sites Grafted onto Dealuminated Beta Zeolite. J. Am. Chem. Soc. 2020, 142, 14674-14687.

(12) Abdelrahman, O. A.; Park, D. S.; Vinter, K. P.; Spanjers, C. S.; Ren, L.; Cho, H. J.; Vlachos, D. G.; Fan, W.; Tsapatsis, M.; Dauenhauer, P. J. Biomass-Derived Butadiene by Dehydra-Decyclization of Tetrahydrofuran. ACS Sustain. Chem. Eng. 2017, 5, 3732-3736.

(13) Yacob, S.; Park, S.; Kilos, B. A.; Barton, D. G.; Notestein, J. M. Vapor-Phase Ethanol Carbonylation with Heteropolyacid-Supported Rh. J. Catal. 2015, 325, 1-8.

(14) Hashimoto, K.; Masuda, T.; Sasaki, H. Measurement of Bronsted Acid and Lewis Acid Strength Distributions of Solid Acid Catalysts Using Chemisorption Isotherms of Hammett Indicators. Ind. Eng. Chem. Res. 1988, 27, 1792-1797.

(15) Gounder, R.; Jones, A. J.; Carr, R. T.; Iglesia, E. Solvation and Acid Strength Effects on Catalysis by Faujasite Zeolites. 
J. Catal. 2012, 286, 214-223.

(16) Liu, H.; Bayat, N.; Iglesia, E. Site Titration with Organic Bases During Catalysis: Selectivity Modifier and Structural Probe in Methanol Oxidation on Keggin Clusters. Angew. Chemie - Int. Ed. 2003, 42, 50725075.

(17) Murphy, B. M.; Letterio, M. P.; Xu, B. Catalyst Deactivation in Pyridine-Assisted Selective Dehydration of Methyl Lactate on NaY. ACS Catal. 2017, 7, 1912-1930.

(18) Murphy, B. M.; Letterio, M. P.; Xu, B. Selectivity Control in the Catalytic Dehydration of Methyl Lactate: The Effect of Pyridine. ACS Catal. 2016, 6, 51175131.

(19) Murphy, B. M.; Letterio, M. P.; Xu, B. Catalytic Dehydration of Methyl Lactate: Reaction Mechanism and Selectivity Control. J. Catal. 2016, 339, 21-30.

(20) Pramod, C. V.; Fauziah, R.; Seshan, K.; Lange, J. P. Bio-Based Acrylic Acid from Sugar via Propylene Glycol and Allyl Alcohol. Catal. Sci. Technol. 2018, 8, 289296.

(21) Liu, L.; Ye, X. P.; Bozell, J. J. A Comparative Review of Petroleum-Based and Bio-Based Acrolein Production. ChemSusChem 2012, 5, 1162-1180. Zhang, X.; Lin, L.; Zhang, T.; Liu, H.; Zhang, X. Catalytic Dehydration of Lactic Acid to Acrylic Acid over Modified ZSM5 Catalysts. Chem. Eng. J. 2016, 284, 934 941.

(23) Zhang, L.; Theng, D. S.; Du, Y.; Xi, S.; Huang, L.; Gao, F.; Wang, C.; Chen, L.; Borgna, A. Selective Conversion of Lactic Acid to Acrylic Acid over Alkali and Alkaline-Earth Metal Co-Modified NaY Zeolites. Catal. Sci. Technol. 2017, 7, 6101-6111.

(24) Yan, B.; Tao, L. Z.; Mahmood, A.; Liang, Y.; Xu, B. Q. Potassium-Ion-Exchanged Zeolites for Sustainable Production of Acrylic Acid by Gas-Phase Dehydration of Lactic Acid. ACS Catal. 2017, 7, 538-550.

(25) Yan, B.; Tao, L. Z.; Liang, Y.; Xu, B. Q. Sustainable Production of Acrylic Acid: Alkali-Ion Exchanged Beta Zeolite for Gas-Phase Dehydration of Lactic Acid. ChemSusChem 2014, 7, 1568-1578.
(26)

Ghantani, V. C.; Lomate, S. T.; Dongare, M. K.; Umbarkar, S. B. Catalytic Dehydration of Lactic Acid to Acrylic Acid Using Calcium Hydroxyapatite Catalysts. Green Chem. 2013, 15, 1211-1217.

(27) Guo, Z.; Theng, D. S.; Tang, K. Y.; Zhang, L.; Huang, L.; Borgna, A.; Wang, C.

Dehydration of Lactic Acid to Acrylic Acid over Lanthanum Phosphate Catalysts: The Role of Lewis Acid Sites. Phys. Chem. Chem. Phys. 2016, 18, 23746-23754.

(28) Ghantani, V. C.; Dongare, M. K.; Umbarkar, S. B. Nonstoichiometric Calcium Pyrophosphate : A Highly e Fficient and Selective Catalyst for Dehydration of Lactic Acid to Acrylic Acid. RSC Adv. 2014, 4, 33319-33326. Bonnotte, T.; Paul, S.; Araque, M.; Wojcieszak, R.; Dumeignil, F.; Katryniok, B. Dehydration of Lactic Acid: The State of The Art. ChemBioEng Rev. 2018, 5, 3456.

(30) Datta, R.; Michael, H. Lactic Acid: Recent Advances in Products, Processes and Technologies - a Review. J. Chem. Technol. Biotechnol. 2006, 81, 1119-1129.

(31) Moljord, K.; Magnoux, P.; Guisnet, M. Coking, Aging and Regeneration of Zeolites XV. Influence of the Composition of HY Zeolites on the Mode of Formation of Coke from Propene at $450^{\circ} \mathrm{C}$. Appl. Catal. A, Gen. 1995, 122, 21-32.

(32) Santacruz, I.; Nieto, M. I.; Moreno, R.; Faraldos, M.; Sastre, E. A Novel Method to Prepare Zeolites with Hierarchical Porosity. Adv. Eng. Mater. 2005, 7, 858861.

(33) Mohan, S. C.; Vijay Solomon, R.; Venuvanalingam, P.; Jothivenkatachalam, K. Encapsulation of a Hexaaza Macrocyclic Nickel(II) Complex in Zeolite Y: An Experimental and Theoretical Investigation. New J. Chem. 2017, 41, 9505-9512.

(34) Hunter, E. P. L.; Lias, S. G. Evaluated Gas Phase Basicities and Proton Affinities of Molecules: An Update. J. Phys. Chem. Ref. Data 1998, 27, 413-656.

(35) Lutz, W.; Lefebvre, L. Zeolite Y: Synthesis, Modification, and Properties - A Case Revisited. Adv. Mater. Sci. Eng. 
2014, 2014, 1-20.

(36) Baerlocher, C.; McCusker, L. B. Database of Zeolite Structures. Available at: http://www.iza-structure.org/databases/ 2014, Accessed online: January 2014. https://doi.org/http://www.izastructure.org/databases/.

(37) Jones, A. J.; Carr, R. T.; Zones, S. I.; Iglesia, E. Acid Strength and Solvation in Catalysis by MFI Zeolites and Effects of the Identity, Concentration and Location of Framework Heteroatoms. J. Catal. 2014, 312, 58-68.

(38) Zhang, J.; Zhao, Y.; Pan, M.; Feng, X.; Ji, W.; Au, C. T. Efficient Acrylic Acid Production through Bio Lactic Acid Dehydration over NaY Zeolite Modified by Alkali Phosphates. ACS Catal. 2011, 1, 3241.

(39) Ozmeral, C. A.; Glas, J. P.; Dasari, R.; Tanielyan, S.; Bhagat, R. D.; Kasireddy, M. R.; Singh, R.; Gnanadesikan, V.; Augustine, R. L.; More, S. US20150038735A1, 2015.

(40) Näfe, G.; López-Martínez, M. A.; Dyballa, M.; Hunger, M.; Traa, Y.; Hirth, T.; Klemm, E. Deactivation Behavior of Alkali-Metal Zeolites in the Dehydration of Lactic Acid to Acrylic Acid. J. Catal. 2015, 329, 413-424.

(41) Sun, P.; Yu, D.; Tang, Z.; Li, H.; Huang, $\mathrm{H}$. NaY Zeolites Catalyze Dehydration of Lactic Acid to Acrylic Acid: Studies on the Effects of Anions in Potassium Salts. Ind. Eng. Chem. Res. 2010, 49, 9082-9087.

(42) Lari, G. M.; Puértolas, B.; Frei, M. S.; Mondelli, C.; Pérez-Ramírez, J. Hierarchical NaY Zeolites for Lactic Acid Dehydration to Acrylic Acid. ChemCatChem 2016, 8, 1507-1514.

(43) Yan, B.; Liu, Z.; Liang, Y.; Xu, B. Acrylic Acid Production by Gas-Phase Dehydration of Lactic Acid over K+ Exchanged ZSM-5: Reaction Variable Effects, Kinetics, and New Evidence for Cooperative Acid-Base Bifunctional Catalysis. Ind. Eng. Chem. Res. 2020, 59, 17417-17428.

(44) Gorte, R. J. What Do We Know about the Acidity of Solid Acids? Catal. Letters 1999, 62, 1-13.
Deshlahra, P.; Iglesia, E. Toward More Complete Descriptors of Reactivity in Catalysis by Solid Acids. ACS Catal. 2016, 6, 5386-5392.

(46) Jones, A. J.; Iglesia, E. The Strength of Brønsted Acid Sites in Microporous Aluminosilicates. ACS Catal. 2015, 5, 5741-5755.

(47) Castellà-Ventura, M.; Akacem, Y.; Kassab, E. Vibrational Analysis of Pyridine Adsorption on the Brønsted Acid Sites of Zeolites Based on Density Functional Cluster Calculations. J. Phys. Chem. C 2008, 112, 19045-19054.

(48) Jeffrey, G. A. An Introduction to Hydrogen Bonding. Oxford Univ. Press 1997, 191200.

(49) Benesi, H. A. Determination of Proton Acidity of Solid Catalysts by Chromatographic Adsorption of Sterically Hindered Amines. J. Catal. 1973, 34, 176178.

(50) Jacobs, P. A.; Heylen, C. F. Active Sites in Zeolites: III. Selective Poisoning of Bronsted Sites on Synthetic Y Zeolites. $J$. Catal. 1974, 34, 267-274.

(51) Aramendí, M. A.; Borau, V.; Jiménez, C.; Marinas, J. M.; Porras, A.; Urbano, F. J. Determination of Acid Sites in Solid Catalysts by Mass Spectrometry. Rapid Commun. Mass Spectrom. 1994, 8, 599602.

(52) Benesi, H.; Winquist, B. Surface Acidity of Solid Catalysts; Advances in Catalysis; Academic Press, 1979.

(53) Ramsahye, N. A.; Bell, R. G. Cation Mobility and the Sorption of Chloroform in Zeolite NaY: Molecular Dynamics Study. J. Phys. Chem. B 2005, 109 (10), 47384747.

(54) Abrioux, C.; Coasne, B.; Maurin, G.; Henn, F.; Boutin, A.; Di Lella, A.; Nieto-Draghi, C.; Fuchs, A. H. A Molecular Simulation Study of the Distribution of Cation in Zeolites. Adsorption 2008, 14 (4-5), 743 754. https://doi.org/10.1007/s10450-0089123-z.

(55) Beauvais, C.; Guerrault, X.; Coudert, F. X.; Boutin, A.; Fuchs, A. H. Distribution of Sodium Cations in Faujasite-Type Zeolite: A Canonical Parallel Tempering 
Simulation Study. J. Phys. Chem. B 2004, 108 (1), 399-404. https://doi.org/10.1021/jp036085i.

(56) Jiao, J.; Kanellopoulos, J.; Wang, W.; Ray, S. S.; Foerster, H.; Freude, D.; Hunger, M.; Gmbh, B. B. Characterization of Framework and Extra-Framework Aluminum Species in Non-Hydrated Zeolite Y by 27Al Spin-Echo, High-Speed MAS, and MQMAS NMR Spectroscopy at B0 $=9.4$ to 17.6 T. Phys. Chem. Chem. Phys. 2005, 7, 3221-3226.

(57) Kumar, G.; Bossert, H.; McDonald, D.; Chatzidimitriou, A.; Ardagh, M. A.; Pang, Y.; Lee, C. S.; Tsapatsis, M.;

Abdelrahman, O. A.; Dauenhauer, P. J. Catalysis-in-a-Box: Robotic Screening of Catalytic Materials in the Time of COVID19 and Beyond. Matter 2020, 3, 805-823.

(58) Maduskar, S.; Teixeira, A. R.; Paulsen, A. D.; Krumm, C.; Mountziaris, T. J.; Fan, W.; Dauenhauer, P. J. Quantitative Carbon Detector (QCD) for Calibration-Free, High-Resolution Characterization of Complex Mixtures. Lab Chip 2015, 15, 440-447.

(59) Choudhary, V. R. TemperatureProgrammed Desorption of Organic Bases on NaY Zeolite under Chromatographic Conditions. J. Chromatogr. 1983, 259, 283-290.

(60) Oliviero, L.; Vimont, A.; Lavalley, J. C.; Sarria, F. R.; Gaillard, M.; Maugé, F. 2,6Dimethylpyridine as a Probe of the Strength of Brønsted Acid Sites: Study on Zeolites. Application to Alumina. Phys. Chem. Chem. Phys. 2005, 7, 1861-1869.

(61) Morterra, C.; Cerrato, G.; Meligrana, G. Revisiting the Use of 2,6-Dimethylpyridine Adsorption as a Probe for the Acidic Properties of Metal Oxides. Langmuir 2001, 17, 7053-7060.

(62) Daniell, W.; Topsøe, N. Y.; Knözinger, H. An FTIR Study of the Surface Acidity of USY Zeolites: Comparison of CO, CD3CN, and C5H5N Probe Molecules. Langmuir 2001, 17, 6233-6239.

(63) McQuarrie, D. A. Statistical Mechanics; Harper \& Row, New York, 1976.

(64) Frisch, M. J.; Trucks, G. W.; Schlegel, H. B.; Scuseria, G. E.; Robb, M. A.;
Cheeseman, J. R.; Scalmani, G.; Barone, V.; Petersson, G. A.; Nakatsuji, H.; Li, X.; Caricato, M.; Marenich, A. V.; Bloino, J.; Janesko, B. G.; Gomperts, R.; Mennucci, B.; Hratch, D. J. Gaussian 16, Revision C.01. Gaussian, Inc., Wallingford CT, 2016.

(65) Ligon, A. P. Theoretical Calculations of the Proton Affinities of N-Aikylamines, nAlkyl Thiols, and n-Alcohols and the Ammonium Affinities of the n-Alcohols. $J$. Phys. Chem. A 2000, 104, 8739-8743.

(66) Wright, J. S.; Rowley, C. N.; Chepelev, L. L. A "universal" B3LYP-Based Method for Gas-Phase Molecular Properties: Bond Dissociation Enthalpy, Ionization Potential, Electron and Proton Affinity and GasPhase Acidity. Mol. Phys. 2005, 103, 815823.

(67) Bondi, A. Van Der Waals Volumes and Radii. J. Phys. Chem. 1964, 68, 441-451.

(68) Bird, R. B.; Stewart, W. E.; Lightfoot, E. N. Transport Phenomena. John Wiley Sons, New York. 1960, 26.

(69) Wang, H.; Frenklach, M. Transport Properties of Polycyclic Aromatic Hydrocarbons for Flame Modeling. Combust. Flame 1994, 96, 163-170.

(70) Treacy, M. M. J.; Foster, M. D. Packing Sticky Hard Spheres into Rigid Zeolite Frameworks. Microporous Mesoporous Mater. 2009, 118, 106-114.

(71) Jelinek, R.; Özkar, S.; Pastore, H. O.; Malek, A.; Ozin, G. A. Guest-Host Interactions in Sodium Zeolite Y: Structural and Dynamical 23Na DoubleRotation NMR Study of H2O, PMe3, $\mathrm{Mo}(\mathrm{CO}) 6$, and $\mathrm{Mo}(\mathrm{CO}) 4(\mathrm{PMe} 3) 2$ Adsorption in Na56Y. J. Am. Chem. Soc. 1993, 115, 563-568.

(72) Moon, D. J.; Lim, W. T. Synthesis and Single-Crystal Structure of Sodium Sulfide Cationic Cluster in the Sodalite Cavity of Zeolite Y (FAU, Si/Al = 1.56). J. Porous Mater. 2020, 27, 1233-1240.

(73) Su, H.; Kim, H. S.; Seo, S. M.; Ko, S. O.; Suh, J. M.; Kim, G. H.; Lim, W. T. Location of $\mathrm{Na}+$ Ions in Fully Dehydrated $\mathrm{Na}+-$ Saturated Zeolite y (FAU, Si/Al = 1.56). Bull. Korean Chem. Soc. 2012, 33, 2785-2788. 


\section{Chem Rxiv ${ }^{\text {Th }}$}

(74) Teixeira, A. R.; Chang, C. C.; Coogan, T.; Kendall, R.; Fan, W.; Dauenhauer, P. J. Dominance of Surface Barriers in Molecular Transport through Silicalite-1. J. Phys. Chem. C 2013, 117, 25615-25621.

(75) Sun, H.; Mumby, S. J.; Maple, J. R.; Hagler, A. T. An Ab Initio CFF93 AllAtom Force Field for Polycarbonates. $J$. Am. Chem. Soc. 1994, 116, 2978-2987.

(76) Han, K. N.; Bernardi, S.; Wang, L.; Searles, D. J. Water Structure and Transport in Zeolites with Pores in One or Three Dimensions from Molecular Dynamics Simulations. J. Phys. Chem. C 2017, 121, 381-391.

(77) Kresse, G.; Furthmüller, J. Efficient Iterative Schemes for Ab Initio TotalEnergy Calculations Using a Plane-Wave Basis Set. Phys. Rev. B - Condens. Matter Mater. Phys. 1996, 54, 11169-11186.

(78) Perdew, J. P.; Burke, K.; Ernzerhof, M. Generalized Gradient Approximation Made Simple. Phys. Rev. Lett. 1996, 77, 38653868.

(79) Blochl, P. E.; Clemens, J. F.; Johannes Schimpl. The Projector Augmented Wave Method: Ab-Initio Molecular Dynamics with Full Wave Functions. Bull. Mater. Sci. 2003, 26, 33-41.

(80) Kresse, G.; Joubert, D. From Ultrasoft Pseudopotentials to the Projector Augmented-Wave Method. 1999, 59, 1119.

(81) Grimme, S.; Antony, J.; Ehrlich, S.; Krieg, H.; Grimme, S.; Antony, J.; Ehrlich, S.; Krieg, H. A Consistent and Accurate $\mathrm{Ab}$ Initio Parametrization of Density Functional Dispersion Correction ( DFT-D ) for the 94 Elements H-Pu. J. Chem. Phys. 2010, 132, 154104-1-29.

(82) Grimme, S.; Ehrlich, S.; Goerigk, L. Effect of the Damping Function in Dispersion Corrected Density Functional Theory. J. Comput. Chem. 2011, 32, 1456-1465.

(83) Humphrey, W.; Dalke, A.; Schulten, K. VMD: Visual Molecular Dynamics. J. Mol. Graph. 1996, 14, 33-38.

(84) Murphy, B. M.; Wu, J.; Cho, H. J.; Soreo, J.; Wang, C.; Ma, L.; Xu, B. Nature and Catalytic Properties of In-Situ-Generated Brønsted Acid Sites on NaY. ACS Catal.
2019, 9, 1931-1942.

Prasomsri, T.; Shetty, M.; Murugappan, K.; Román-Leshkov, Y. Insights into the Catalytic Activity and Surface Modification of $\mathrm{MoO} 3$ during the Hydrodeoxygenation of Lignin-Derived Model Compounds into Aromatic Hydrocarbons under Low Hydrogen Pressures. Energy Environ. Sci. 2014, 7, 2660-2669.

(86) Bartholomew, C. H. Mechanisms of Catalyst Deactivation. Appl. Catal. A Gen. 2001, 212, 17-60.

(87) Fogler, S. H. Elements of Chemical Reaction Engineering, Printice- Hall International Editions; 1987. 